\title{
EL ACTO Y CRIMEN DE AGRESIÓN EN EL DERECHO INTERNACIONAL PÚBLICO Y SU REPERCUSIÓN EN LAS RELACIONES POLÍTICAS INTERNACIONALES*
}

\author{
Efrén Gustavo MARQUÉS RUEDA**
}

\begin{abstract}
RESUMEN: Este trabajo realiza un análisis jurídico-político internacional sobre el devenir histórico y estado actual que guardan los debates y propuestas en torno a la definición del acto y crimen de agresión, así como de los principales obstáculos a los que se ha enfrentado y se seguirá enfrentado la comunidad internacional para alcanzar los acuerdos políticos necesarios para adoptar una definición precisa y vinculante sobre el crimen en cuestión.
\end{abstract}

ABSTRACT: This work is about of a legal-political international analysis of the historical happening and current state that keep the debates and proposals around the definition from the act and crime of aggression, as well as of the main obstacles which it has faced and it will be followed faced the international community to reach the political agreements necessary to adopt a precise and binding definition on the crime at issue.

RÉSUMÉ: Cet travail effectue une analyse juridique-politique internationale sur devenir historique et état actuel que gardent les débats et les propositions autour de la definition $d u$ acte et crime d'agression, ainsi que des principaux obstacles à auxquels il a fait face et on sera encore fait face la communauté internationale pour conclure les accords politiques nécessaires pour adopter une définition précise et obligatoire sur le crime en question.

* Artículo recibido el 18 de julio de 2008 y aceptado para su publicación el 7 de agosto de 2008.

** Doctorante en ciencias políticas con orientación en relaciones internacionales por la Facultad de Ciencias Políticas y Sociales de la UNAM. Profesor de asignatura en la materia Tratados internacionales, derecho internacional, y tutor del Seminario de relaciones jurídicas internacionales en la misma Facultad. 
SUMARIO: I. Introducción. II. La referencia obligada. La prohibición al uso de la fuerza en las relaciones internacionales. III. La definición del acto de agresión y la responsabilidad internacional del Estado. IV. La definición del crimen de agresión. Un asunto pendiente en la agenda jurídico-política de las relaciones internacionales. V. Reflexiones finales.

\section{INTRODUCCIÓN}

La agresión es considerada como la manifestación más flagrante del uso de la fuerza entre Estados y una de las principales amenazas a la paz y la seguridad internacionales. La necesidad de delimitar con precisión el significado y alcances de la agresión sólo cobraron importancia en la medida en que la comunidad internacional prohibió el uso de la fuerza como recurso lícito para la solución de controversias entre Estados.

Lograr la adopción de una definición precisa y plenamente aceptada de la agresión se ha convertido en una de las principales tareas pendientes de la comunidad internacional debido a tres grandes razones. En primer lugar, la agresión constituye tanto un acto ilícito de un Estado contra otro como un crimen internacional susceptible de engendrar la responsabilidad penal individual de gobernantes y funcionarios de alto nivel; en segundo lugar, su naturaleza y connotaciones jurídico-políticas han provocado el surgimiento de posturas políticas y doctrinales prácticamente irreconciliables, y, en tercer lugar y más importante aún, la falta de voluntad política de los Estados y su temor a que su accionar internacional se vea restringido por la adopción de una definición precisa sobre el acto y el crimen de agresión han obstaculizado de manera considerable los esfuerzos realizados al respecto.

Así, mientras que la Organización de las Naciones Unidas, tras años de una encomiable labor, sólo ha logrado la adopción de una definición declarativa del acto de agresión, el crimen se encuentra indefinido debido a la falta de acuerdos políticos y a que el quehacer de muchos Estados se ha quedado en el terreno de las buenas intenciones. Lo anterior ha generado un vacío jurídico ampliamente aprovechado por algunos Estados para recurrir constantemente al uso de la fuerza en sus relaciones internacionales, sin recibir sanción alguna.

Doctrinalmente hablando, la agresión, como acto de fuerza, se inscribe en el campo de estudio del derecho internacional público, y parti- 
cularmente, en los ámbitos temáticos relativos al uso de la fuerza y a la responsabilidad internacional del Estado. Sin embargo, a raíz de la incorporación de la agresión como uno de los crímenes internacionales competencia de la Corte Penal Internacional se ha abierto una nueva página de la polémica, politizada e inconclusa labor de la comunidad internacional, iniciada en el contexto de los históricos Tribunales de Nüremberg y Tokio, para adoptar una definición del crimen de agresión en el marco general del derecho internacional penal, y de la responsabilidad internacional penal individual en particular.

Al igual que aconteció durante los trabajos realizados por las Naciones Unidas para elaborar una definición del acto de agresión, los esfuerzos encaminados a que la Corte Penal Internacional pueda contar con una definición del crimen de agresión se encuentran estancados por la falta de acuerdos en torno a dos cuestiones fundamentales; en primer lugar, los elementos que debe contener la definición del crimen a incorporar en el Estatuto de Roma (debate enfoque genérico-enfoque específico y debate enfoque monístico-enfoque diferenciado), y, en segundo lugar, las condiciones en las cuáles la corte ejercerá su competencia sobre el crimen de agresión (debate relativo a las relaciones y facultades entre la Corte Penal Internacional y el Consejo de Seguridad de las Naciones Unidas en la determinación de actos estatales de agresión).

En el presente trabajo se realiza un análisis jurídico-político internacional sobre el devenir histórico y el estado actual que guardan los debates y propuestas en torno a la definición del acto y crimen de agresión, así como de los principales obstáculos a los que se ha enfrentado y se seguirá enfrentado la comunidad internacional para alcanzar los acuerdos políticos necesarios para adoptar un definición precisa y vinculante sobre el crimen en cuestión.

\section{LA REFERENCIA OBLIGADA. LA PROHIBICIÓN AL USO DE LA FUERZA EN LAS RELACIONES INTERNACIONALES}

Durante gran parte de la historia del hombre la guerra fue el principal medio de solución de controversias entre los pueblos, naciones y Estados. Su empelo como instrumento cotidiano, lícito y legitimo de sanción y solución de controversias sentó las bases del denominado derecho a la guerra (ius ad bellum), las del ordenamiento jurídico encargado de regular el inicio, conducción, terminación y régimen de neutralidad de los 
conflictos bélicos, es decir, el derecho de guerra (ius in bellum), ${ }^{1}$ así como las del régimen legal humanitario destinado a proteger a todos aquellos individuos que no participan directamente en las hostilidades (poblaciones civiles) o que han dejado de hacerlo (heridos, enfermos y náufragos de las fuerzas armadas y prisioneros de guerra). ${ }^{2}$

Aunada a la pretendida justificación de sancionar o solucionar una controversia, los Estados también han recurrido a la guerra o uso de la fuerza armada "para defender los que parecían sus más vitales e importantes intereses en un momento determinado", ${ }^{3}$ invocando los principios de autoconservación, autoprotección, autoayuda o necesidad.

En 1837 un grupo de insurgentes canadienses que luchaba contra el gobierno británico en Canadá contrató el barco Caroline, atracado en el puerto de Schlosser, Estados Unidos, con el objetivo de allegarse de suministros bélicos. Antes de que la embarcación abandonara el territorio estadounidense, el gobierno británico ordenó la destrucción del barco. Estados Unidos presentó a su homólogo británico una queja por la violación de su soberanía territorial y una explicación en la que se demostrará que Gran Bretaña había actuado en legítima defensa y con base en una necesidad inmediata y apremiante que no dio oportunidad para la elección de medios alternativos al del uso de la fuerza. Gran Bretaña no contestó la queja, pero dejó en claro que había actuado por necesidad, ante la amenaza inminente que representaba para su seguridad el envío de suministros bélicos a los insurgentes canadienses. ${ }^{4}$

1 También conocido como derecho de La Haya debido a la importancia de las Conferencias de Paz de La Haya de 1899 y 1907 en la recopilación y codificación en instrumentos internacionales convencionales de las denominadas leyes y costumbres de guerra (derecho consuetudinario).

2 La regulación humanitaria de la guerra dio origen al derecho internacional humanitario, rama del derecho internacional encargada de regular la observancia de los derechos humanos en situaciones de conflicto bélico, y cuya codificación alcanzó su grado máximo en las cuatro Convenciones de Ginebra de 1949 y sus dos Protocolos Adicionales del 1977.

3 Skubiszewski, K. J., "Uso de la fuerza por parte de los Estados. Seguridad colectiva. Derecho de guerra y de neutralidad", en Sorensen, Max (ed.), Manual de derecho internacional público, México, FCE, 1998, p. 700.

4 El incidente del Caroline se ha convertido en referencia obligada en el estudio de la legítima defensa ante una amenaza inminente. Asimismo, algunos doctrinarios contemporáneos han retomado este caso para justificar la legalidad de la denominada "legítima defensa preventiva", defendida y aplicada por Estados Unidos en su lucha contra 
La historia nos proporciona un gran número de hechos históricos en los cuales se han invocado dichos principios para justificar el recurso a la guerra como el medio idóneo, de acuerdo a la coyuntura, para salvaguardar la existencia o independencia de los Estados. Desde la perspectiva de la política internacional, principalmente del equilibrio de poder, la guerra es un instrumento de política nacional altamente efectivo para conservar el statu quo internacional o modificarlo en beneficio de los Estados que cuentan con la capacidad material para obtener ventajas políticas, económicas y territoriales mediante un conflicto bélico.

La guerra representa un instrumento de poder sumamente efectivo mientras se encuentre limitada a un espacio y tiempo determinados, y no afecte los intereses primordiales de los Estados que se encuentran involucrados. Sin embargo, cuando un conflicto bélico desborda los límites contemplados y adquiere magnitudes inesperadas, la guerra pierde su efectividad y los Estados se ven en la necesidad de recurrir a mecanismos alternativos para garantizar la viabilidad del sistema internacional. La Primera Guerra Mundial demostró las graves consecuencias humanitarias y materiales que trae consigo una conflagración de magnitudes mundiales, y puso de manifiesto la necesidad de la comunidad internacional por impedir la repetición de acontecimientos de tales proporciones.

El Pacto de la Sociedad de las Naciones (PSN) de 1919 estableció algunas de las primeras disposiciones legales tendientes a promover la solución pacífica de controversias internacionales, el desarme, y a limitar al recurso a la guerra como último mecanismo de solución de diferencias. El artículo 11 del Pacto declaraba expresamente que "toda guerra o amenaza de guerra... interesa a la sociedad entera y que ésta debe adoptar las medidas adecuadas para salvaguardar eficazmente la paz de las naciones". A su vez, el artículo 12 disponía que:

todos los miembros de la sociedad convienen en que, si surgiera entre ellos una divergencia susceptible de provocar una ruptura, la someterán al procedimiento del arbitraje o a un arreglo judicial, o al examen del Consejo. Convienen además que, en caso alguno, deben recurrir a la guerra antes 
de la expiración de un plazo de 3 meses desde el fallo arbitral o judicial, o el informe del Consejo.

Algunos autores sostienen que las disposiciones del PSN sólo constituían "unas débiles medidas de precaución para la domesticación de la solución de los conflictos por medio de la guerra. La obligación de intentar solucionar las controversias en primer lugar acudiendo a determinados procesos para la solución de conflictos no constituye un instrumento efectivo para la prevención de la guerra". ${ }^{5}$ Desde nuestro particular punto de vista, las disposiciones del pacto responden al espíritu idealista e internacionalista con que fue elaborado, es decir, los redactores de dicho instrumento confiaban en que las devastadoras consecuencias de la Gran Guerra hubieran servido de escarmiento suficiente para no repetirlas. Desde una perspectiva política, tales disposiciones eran completamente viables ya que, en un contexto de posguerra, los Estados se encontraban preocupados de que su debilidad fuera aprovechada por otros Estados para iniciar una nueva conflagración; sin duda alguna, los Estados no estaban dispuestos a dejar su seguridad en manos de una organización internacional en ciernes. Por tal motivo, es completamente entendible que el pacto sólo estableciera "la llamada moratoria de guerra". ${ }^{6}$

Débiles, insuficientes, o como quiera adjetivárseles, lo cierto es que los artículos del pacto deben ser interpretados de manera sistemática, puesto que, aunque el artículo 12 permite la guerra como último recurso, el artículo 13, inciso 4, establece el compromiso de los Estados de cumplir de buena fe las sentencias arbitrales o judiciales pronunciadas y a no recurrir a la guerra. Además, el artículo 12 fue la primera disposición legal de carácter taxativo que limitó a la guerra como el último recurso para la solución de diferencias, sin dejar de mencionar la prohibición expresa de toda guerra iniciada en contravención de los compromisos contraídos por los Estados en los artículos 12, 13 o 15 del pacto, ${ }^{7}$ y de las guerras de agresión contempladas en el artículo 10.

5 Herdegen, Matthias, Derecho internacional público, México, UNAM, Instituto de Investigaciones Jurídicas-Fundación Konrad Adenauer Stiftug, 2005, p. 246.

6 Méndez Silva, Ricardo, "El uso de la fuerza y el derecho internacional humanitario", en Fraidenraij y Méndez Silva (comps.), Elementos de derecho internacional humanitario, México, UNAM, Instituto de Investigaciones Jurídicas, 2001, p. 73.

7 El artículo 16, párrafo 1, disponía que: si un miembro de la sociedad recurre a la guerra, contrariamente a los compromisos contraídos en los artículos 12, 13 o 15, es ipso 
Los esfuerzos internacionales en favor de la paz y el desarme realizados durante la segunda década del siglo XX se vieron reforzados por la adopción del Tratado General para la Renuncia de la Guerra del 27 de agosto de 1928, mejor conocido como Pacto de París o Pacto Briand-Kellogg (PBK), a través del cual los Estados parte:

persuadidos de que ha llegado el momento de proceder a una sincera renuncia a la guerra como instrumento de política nacional, a fin de que las relaciones pacíficas y amistosas que actualmente existen entre sus pueblos puedan ser perpetuadas; convencidos de que cualquier cambio en sus relaciones recíprocas no debe ser buscado sino por procedimientos pacífi$\cos . .$. y de que toda potencia firmante que intentara en lo sucesivo desarrollar sus intereses nacionales mediante el recurso a la guerra deberá ser privada del beneficio del presente Tratado, ${ }^{8}$ declararon solemnemente que: condenan el recurso a la guerra para la resolución de los desacuerdos internacionales, y que renuncian a ella, en tanto que instrumento de política nacional, en sus relaciones recíprocas (artículo 1o.).

El PBK rebasó de manera significativa los alcances de la moratoria de guerra incorporada en el PSN, al establecer una renuncia total a la guerra como instrumento de política nacional. Asimismo, y como en su momento lo hiciera el artículo 10 del PSN, el preámbulo del PBK contemplaba una condena y prohibición implícita de las guerras de agresión, al establecer que toda potencia firmante que recurriera a la guerra para obtener intereses nacionales sería privada de los beneficios del presente tratado, es decir, el uso de la fuerza en contravención del pacto ameritaba una respuesta similar; en otras palabras, permitía el recurso a la guerra en legítima defensa ante la violación del tratado por parte de un Estado.

Tanto el PSN como el PBK legaron grandes aportaciones al derecho internacional al limitar el recurso a la guerra como último mecanismo de solución de diferencias, el primero, y a situaciones de legítima defensa

facto considerado como habiendo cometido un acto de guerra contra todos los demás miembros de la sociedad. Éstos se comprometen a romper inmediatamente con él todas las relaciones comerciales o financieras, a prohibir todas las relaciones entre sus nacionales y los del Estado en ruptura del pacto y a hacer cesar todas las comunicaciones financieras, comerciales o personales entre los nacionales de este Estado y los de cualquier otro Estado, miembro o no de la sociedad.

8 Preámbulo del Tratado General para la Renuncia de la Guerra del 27 de agosto de 1928. 
individual o colectiva, el segundo. Sin embargo, esta gran aportación también significó la principal debilidad de los dos instrumentos jurídicos, ya que la utilización de los términos "guerra", "guerra de agresión" y "recurso a la guerra" impidieron su aplicación en aquellas situaciones en que los Estados recurrieron al uso de la fuerza armada sin declararse jurídicamente en estado de guerra. Skubiszewski sostiene que "la utilización de tales términos preparó el terreno para su interpretación restrictiva y técnica en la práctica de los Estados". ${ }^{9}$ En efecto, en contravención de las obligaciones adquiridas en los pactos antes mencionados, Japón invadió el territorio chino de Manchuria en 1931, dando inició a una guerra no declarada. La Sociedad de las Naciones (SDN) no tomó acciones efectivas para condenar y sancionar el accionar japonés, situación que sentó un pésimo precedente sobre la credibilidad y fortaleza de la organización para mantener la paz y seguridad internacionales. Cuando la SDN quiso imponer sanciones al gobierno italiano por la invasión de Etiopía (1935-1936) ningún Estado miembro las aplicó de manera efectiva. Sólo en 1939, y por razones más políticas que jurídicas, se determinó la expulsión de la Unión Soviética de la Sociedad, tras la invasión de Finlandia.

La falta de voluntad política de los Estados para cumplir de manera efectiva con el compromiso de no recurrir a la guerra, así como las debilidades jurídico-políticas de la SN, propias de una organización en ciernes, no impidieron el estallido de la Segunda Guerra Mundial, pero pusieron de manifiesto la necesidad de la comunidad internacional por establecer mecanismos más efectivos y rígidos para garantizar la paz y la seguridad internacionales

El sistema internacional erigido al finalizar la Segunda Guerra Mundial tuvo como objetivo principal garantizar la paz y seguridad internacionales mediante una efectiva prohibición de la amenaza al uso de fuerza en las relaciones internacionales y el compromiso de los Estados para solucionar sus diferencias por medios pacíficos respetando en todo momento su igualdad jurídica, independencia política, integridad territorial, y soberanía y jurisdicción en el manejo de los asuntos internos. El artículo 2o., párrafo 4, de la Carta de la Organización de las Naciones Unidas (CONU) estableció que: "Los Miembros de la Organización, en sus relaciones internacionales, se abstendrán de recurrir a la amenaza o al uso de la fuerza contra la integridad territorial o la independencia política de cual-

9 Skubiszewski, K. J., op. cit., nota 3, p. 684. 
quier Estado, o en cualquier otra forma incompatible con los Propósitos de las Naciones Unidas".

El régimen jurídico en materia de prohibición de la guerra incorporado en la CONU reviste gran importancia para el derecho internacional por las siguientes razones; en primer lugar, es el primer instrumento jurídico internacional que incorpora una prohibición expresa a la amenaza o al uso de la fuerza en las relaciones internacionales; dicha prohibición se encuentra redactada "en forma imperativa"10 de la siguiente manera: "los miembros de la Organización, en sus relaciones internacionales, se abstendrán de recurrir a la amenaza o al uso de la fuerza"; en segundo lugar, amplía la prohibición a la "amenaza al uso de la fuerza", figura no contemplada en los documentos elaborados en el periodo de entreguerras; en tercer lugar, deja claramente establecido que únicamente se refiere a la amenaza o al uso de la fuerza entre Estados, es decir, no contempla otros sujetos internacionales, lo cual es entendible debido a la época en que fue concebida la CONU.

El párrafo 4 del artículo 2o. constituyó la "máxima expresión de la prohibición de la guerra, y se convirtió en la piedra angular del sistema de las Naciones Unidas"; 11 además, supuso "la cristalización de todo un proceso anterior de prohibición gradual del uso individual de la fuerza" ${ }^{12} \mathrm{La}$ incorporación de la prohibición a la amenaza o al uso de la fuerza como principio de la CONU y el reconocimiento, aceptación y aplicación del mismo por parte de los Estados y órganos de las Naciones Unidas ha permitido que dicho principio se convierta en una norma imperativa (ius cogens) de derecho internacional. Además, dicho artículo refleja la preocupación de los redactores de la CONU por utilizar términos más amplios como "uso de la fuerza" y "amenaza del uso de la fuerza" que no pudieran ser interpretados de manera restrictiva y técnica. No obstante, esta gran aportación, los alcances y significado del término "uso de la fuerza" han sido objeto de un gran debate interpretativo, ya que la Carta en ningún momento específica si sólo se prohíbe el uso de la

10 Méndez Silva, Ricardo, op. cit., nota 6, p. 78.

11 Ibidem, p. 76.

12 Gutiérrez Espada, Cesáreo, “El 'uso de la fuerza' en el Informe del Secretario General de Naciones Unidas preparatorio de la Cumbre de Jefes de Estado y de Gobierno (septiembre de 2005)", Revista Electrónica de Estudios Internacionales, España, núm. 10, 2005, p. 9, en http://www.reei.org. 
fuerza armada o también otras modalidades de fuerza como la política diplomática o económica. ${ }^{13}$

Para dilucidar los alcances de la obligación jurídica incorporada en el artículo 2o., párrafo 4 debemos realizar una interpretación sistemática de la Carta, de su propósito fundamental y del contexto internacional en que fue adoptada. Este artículo tiene su fundamento en el artículo 1o., párrafo 1, de la Carta, el cual establece como uno de los propósitos fundamentales de la Organización de las Naciones Unidas (ONU), "mantener la paz y la seguridad internacionales, y con tal fin: tomar medidas colectivas eficaces para prevenir y eliminar amenazas a la paz, y para suprimir actos de agresión u otros quebrantamientos de la paz". Siendo el mantenimiento de la paz el propósito fundamental de la ONU, podemos concluir, prima facie, que la prohibición a recurrir a la amenaza o al uso de la fuerza es de carácter general y no se limita a los casos en que se emplee únicamente la fuerza armada o física o cuando ésta se dirija contra la integridad territorial o la independencia política de cualquier Estado, sino también, como lo menciona el propio párrafo 4 del artículo 2o., a aquellas situaciones en que se atente contra los propósitos de las Naciones Unidas.

Dicha conclusión se refuerza si tomamos en cuenta que la CONU es un ejemplo típico de desarrollo progresivo del derecho internacional, por lo tanto, sería incongruente sostener que la prohibición al uso de la fuerza redactada en la Carta establece obligaciones análogas o menores a las de 1919 y 1928 que no fueron capaces de impedir el estallido de la guerra de 1939. Además, "las modificaciones en el derecho después de 1919, estaban expresamente destinadas a eliminar de la vida internacional la guerra y otras manifestaciones de fuerza". ${ }^{14}$

Pese a que los alcances del artículo 2o., párrafo 4, continúan siendo objeto de debate tanto para algunos doctrinarios como para los Estados, la práctica internacional "refleja una tendencia favorable hacia una interpretación más amplia del concepto fuerza... lo cual tiene un significado

13 Una intervención militar de un Estado contra otro implica el uso de la fuerza armada y atenta contra la integridad territorial y la independencia política del Estado afectado; empero, la intervención política, diplomática o económica en los asuntos internos de un Estado también constituye una modalidad del uso de la fuerza que atenta contra la independencia política del Estado afectado, aunque no esté presente el elemento militar en dicho acto.

14 Skubiszewski, K. J., op. cit., nota 3, p. 686. 
esencial para el desarrollo de las relaciones normales entre los Estados", ${ }^{15}$ y para evitar que se pretenda justificar su ejercicio mediante una "interpretación elástica del régimen de uso de la fuerza en casos concretos y para validar agresiones". ${ }^{16}$ La prohibición al recurso de la amenaza o al uso de la fuerza debe ser interpretada de manera amplia y como una obligación jurídica general. Sólo la propia Carta contempla los casos en que el recurso a la fuerza es legítimo y compatible con sus propósitos fundamentales.

La Carta prevé tres grandes excepciones a la prohibición del uso de la fuerza, a saber: la legitima defensa individual o colectiva (artículo 51), el uso de la fuerza como parte de medidas adoptadas por el Consejo de Seguridad de las Naciones Unidas (CS) para mantener o restablecer la paz y la seguridad internacionales (artículo 42), y el uso de la fuerza por organismos regionales como parte de medidas coercitivas previamente aprobadas por el Consejo de Seguridad (artículo 53). A estas tres excepciones debe añadirse el reconocimiento realizado por las Naciones Unidas del derecho de los pueblos y naciones coloniales o bajo dominación extranjera a recurrir al uso de la fuerza para alcanzar su independencia política y autodeterminación. ${ }^{17}$

El artículo 51 establece que:

Ninguna disposición de esta Carta menoscabará el derecho inmanente de legítima defensa, individual o colectiva, en caso de ataque armado contra un Miembro de las Naciones Unidas, hasta tanto que el Consejo de Seguridad haya tomado las medidas necesarias para mantener la paz y la seguridad internacionales. Las medidas tomadas por los Miembros en ejercicio del derecho de legítima defensa serán comunicadas inmediatamente al Consejo de Seguridad y no afectarán en manera alguna la autoridad y responsabilidad del Consejo conforme a la presente Carta para ejercer en cualquier momento la acción que estime necesaria con el fin de mantener o restablecer la paz y la seguridad internacionales.

15 Tunkin, Gregory I., El derecho y la fuerza en el sistema internacional, trad. de Manuel Becerra, México, UNAM, Instituto de Investigaciones Jurídicas, 1989, p. 46.

16 Méndez Silva, Ricardo, op. cit., nota 6, p. 77.

17 Este derecho ha sido reconocido por la Asamblea General de las Naciones Unidas en su resolución 1514 (XV) de 1960 relativa a la autodeterminación de los pueblos, y en el artículo 7o. del anexo de la resolución 3314 (XXIX) relativa a la definición de la agresión. 
La legítima defensa "no constituye una excepción del principio que prohíbe el uso inicial de la fuerza — sino, más bien- es un derecho a la autodefensa para responder a la agresión de otro Estado". ${ }^{18}$ Tanto la doctrina como la práctica reconocen que la legítima defensa es una respuesta necesaria o urgente (no hay tiempo para recurrir a otros medios), inmediata (ya que constituye una reacción) y proporcional (su objetivo es responder al ataque armado más no agudizarlo y extenderlo) encaminada a repeler un ataque armado (agresión armada) consumado o un ataque inminente (en marcha) de un Estado contra otro, que pone en riesgo la supervivencia del Estado agredido. Este reconocimiento fue confirmado por la Corte Internacional de Justicia en el asunto relativo a las "Actividades militares y paramilitares en y contra Nicaragua (Nicaragua c. Estados Unidos 1984), al sostener que en el supuesto de la legítima defensa... este derecho sólo puede ser ejercido si el Estado interesado ha sido victima de una agresión armada". ${ }^{19}$

Pese a existir este reconocimiento, países como Estados Unidos pretenden ejercer un supuesto derecho de legítima defensa preventiva ante situaciones de "amenaza latente" a fin de garantizar la seguridad y supervivencia de su Estado. Esta posición no ha sido bien recibida por los miembros de la comunidad internacionales en razón del amplísimo margen de subjetividad que puede ser empleado para determinar en qué situaciones podría ejercerse tal derecho. El derecho internacional contemporáneo es claro, cualquier tipo de amenaza debe ser resuelta por medios pacíficos; el uso de la fuerza sólo procede ante la existencia de un ataque armado previo.

El derecho a la legítima defensa puede ser ejercido de forma individual (por el Estado atacado o agredido) o colectiva. "Esta última estaría configurada por el derecho de un Estado a prestar ayuda a otro Estado, al haber sido atacado por un tercer Estado. Este tipo de legítima defensa puede resultar de un acuerdo previo de los Estados o bien de la solicitud

18 Tunkin, Gregory I., op. cit., nota 15, p. 48.

19 Sentencia de la Corte Internacional de Justicia sobre cuestiones de competencia y admisibilidad relativas al asunto de las "Actividades militares y paramilitares en y contra Nicaragua” (Nicaragua c. Estados Unidos), Internacional Court of Justice, Reports, 1984, p. 150 . 
de ayuda formulada por el Estado objeto de la agresión". ${ }^{20}$ Los supuestos de "legítima defensa colectiva suelen enmarcarse en una doble práctica de los Estados, de un lado, acuerdos bilaterales de ayuda mutua para supuestos en que alguno de los Estados sea objeto de ataque. El segundo mecanismo, y hoy la práctica usual y preocupante, es la existencia de mecanismos multilaterales institucionalizados", ${ }^{21}$ los cuales se inscriben en los acuerdos y organismos regionales facultados para entender de asuntos relacionados con el mantenimiento de la paz y la seguridad internacionales previstos en los artículos 52 y 53 de la CONU.

Los organismos multilaterales no pueden ser catalogados como mecanismos de legítima defensa colectiva, ya que desvirtúan el elemento de necesidad inherente a la misma al ser instancias creadas con anterioridad a la ocurrencia del ataque armado y con el objetivo expreso de ejercer el uso de la fuerza en situaciones concretas, siempre y cuando el CS haya emitido una autorización al respecto. En este sentido, los mecanismos multilaterales deben ser identificados como instrumentos de seguridad colectiva jerárquicamente supeditados a las medidas adoptadas por el CS.

Ahora bien, el uso de la fuerza por parte del CS encuentra su fundamento jurídico en el artículo 24 de la Carta, en el cual se confiere al Consejo la responsabilidad primordial de mantener la paz y la seguridad internacionales. Con base en esta responsabilidad, el CS tiene la facultad para determinar la existencia de amenazas a las paz, quebrantamientos a la paz o actos de agresión (artículo 39) y adoptar las medidas que considere pertinentes (coercitivas o no coercitivas) y necesarias para garantizar la estabilidad del sistema internacional (artículos 41 y 42). En otras palabras, el uso legal de la fuerza, tanto en la modalidad de fuerza diplomática, política y económica, como en la de fuerza armada, es monopolio del CS.

La prohibición a la amenaza o al uso de la fuerza alcanzó su más grande regulación en la CONU. Sin embargo, y de manera paradójica, la manifestación más flagrante del uso ilegal de la fuerza, es decir la agresión, no fue reglamentada en la Carta, generando un vacío jurídico que tardó casi tres décadas en ser llenado mediante la adopción de una defini-

20 Acosta Estévez, José B., "La operación Libertad Duradera y la legítima defensa a la luz de los atentados del 11 de septiembre de 2001", Anuario Mexicano de Derecho Internacional, vol. VI, 2006, p. 36.

21 Citado por Acosta Estévez, José B., idem. 
ción del acto de agresión más o menos reconocida y aceptada por los Estados. En el siguiente apartado nos adentraremos en el estudio del largo y difícil camino recorrido por la ONU para lograr el consenso jurídico-político necesario que permitiera la adopción de dicha definición.

\section{LA DEFINICIÓN DEL ACTO DE AGRESIÓN Y LA RESPONSABILIDAD INTERNACIONAL DEL ESTADO}

El término agresión se suma a una larga lista de vocablos y conceptos de naturaleza y connotaciones jurídico-políticas que ha dado lugar a grandes reflexiones doctrinales, interpretaciones y aplicaciones diversas en la práctica de los Estados, así como a la falta de consenso para alcanzar definiciones plenamente aceptadas y reconocidas por los miembros de la comunidad internacional. Términos como uso de la fuerza, amenazas a la paz, quebrantamiento de la paz, agresión, etc., han sido objeto de amplios e inconclusos debates, que a lo largo de los años se han ido politizando y prolongando de manera innecesaria, debido a dos grandes razones: en primer lugar, a la falta de voluntad política y al temor de algunos Estados porque su accionar internacional se vea restringido por la adopción de definiciones precisas que a la postre se conviertan en impedimentos legales para interpretarlos de manera arbitraria a fin de justificar el uso de la fuerza armada en situaciones concretas. Y, en segundo lugar, debido a la interpretación y aplicación ambivalente, unas veces política y otras jurídica, de que han sido objeto dichos términos por parte de los principales órganos de las Naciones Unidas, en especial, el Consejo de Seguridad.

En materia de agresión, la carencia de una definición precisa se remonta al Tratado de Versalles de 1919, en el cual, "las potencias vencedoras de la Primera Guerra Mundial catalogaron, por primera vez en la historia, a la guerra iniciada por Alemania como de agresión". ${ }^{22}$ Más allá del valor histórico de la declaración incorporada en ese tratado, el mismo no aportó una definición sobre la agresión. Esta misma situación se repitió en el Pacto de la Sociedad de las Naciones (PSN), parte integrante del Tratado de Versalles, cuyo artículo 10 establecía que:

22 Marqués, Efrén, El derecho internacional penal frente a los crimenes contra la humanidad: un estudio comparativo de los casos Slobodan Milosevic y Augusto Pinochet, México, UNAM, Facultad de Ciencias Políticas y Sociales, 2004, p. 46. 
Los miembros de la sociedad se comprometen a respetar y a mantener contra toda agresión exterior la integridad territorial y la independencia política presente de todos los miembros de la sociedad. En caso de agresión, de amenaza o de peligro de agresión, el Consejo emitirá opinión sobre los medios de asegurar la ejecución de está obligación.

Del artículo antes transcrito se deduce fácilmente la carencia de una definición de la agresión, empero, aporta cuatro elementos de gran importancia para la determinación y atención del acto: a) la agresión es un acto contrario al derecho internacional; $b$ ) su naturaleza es exterior o internacional, es decir, de un Estado contra otro; c) su objetivo es atentar contra la integridad territorial y la independencia política de los Estados, y d) el Consejo de la Sociedad tenía la facultad para determinar la existencia de actos de agresión, de amenaza o peligro de agresión, y adoptar las medidas pertinentes para garantizar la paz y seguridad internacionales. La prohibición de la agresión contemplada en el PSN fue ampliada por el Pacto Briand-Kellogg (PBK) de 1928, al establecer el compromiso de los Estados parte de renunciar a la guerra como instrumento de su política nacional. A partir de este momento, la guerra dejó de ser un recurso lícito en las relaciones internacionales; concomitantemente, toda iniciación de un conflicto bélico, mediara o no declaración de guerra, pasó a constituir un acto de agresión.

Aunado a estos notables esfuerzos en materia de agresión, debemos mencionar los tratados firmados por la Unión Soviética con Persia en 1927, Francia en 1935, y China en 1937, en los cuales las partes contratantes se comprometieron a no ejecutar ningún acto de agresión de ninguna clase contra la otra parte contratante; los tratados firmados por la propia Unión Soviética en 1933 con diferentes Estados, en los que se incluía una definición casuística de los diversos actos constitutivos de agresión ${ }^{23}$ así como la resolución de la Asamblea de la Sociedad de las

23 En tales tratados se consideraban agresivos los siguientes actos: a) La declaración de guerra a otro Estado. b) La invasión por sus fuerzas armadas, aun sin declaración de guerra, del territorio de otro Estado. c) El ataque por sus fuerzas terrestres, navales o aéreas, aun sin declaración de guerra, del territorio, de los navíos o de las aeronaves de otro Estado. d) El bloqueo naval de las costas de los puertos de otro Estado. e) El apoyo dado a bandas armadas que formadas sobre su territorio hayan invadido el territorio de otro Estado, y negativa, a pesar de la petición de otro Estado, de tomar sobre su propio terri- 
Naciones de septiembre de 1927, en la que se afirmaba la convicción de los Estados miembros de que "una guerra de agresión nunca puede servir como medio para resolver disputas internacionales, y es, por tanto, un crimen internacional, y que finalizaba señalando que, se prohíben, y siempre se prohibirán, todas las guerras de agresión", y la resolución de 1928, adoptada por la Sexta Conferencia Panamericana, en la que se declaraba que "dado que la guerra de agresión constituye un crimen contra la especie humana, toda agresión es ilícita y como tal se declara prohibida".

De los anteriores documentos destacan los tratados de 1933 celebrados por la Unión Soviética y las resoluciones de la SN y la Sexta Conferencia Panamericana. Los primeros proporcionaron las primeras definiciones de carácter casuístico sobre la agresión; por su parte, las segundas confirmaron la convicción jurídica (opinio iuris) de los Estados relativa a que la agresión era un acto prohibido y que su comisión constituía un crimen en contra de la especie humana.

No obstante estos loables avances, los esfuerzos internacionales encaminados a lograr el consenso necesario para la aceptación de una definición de la agresión se vieron interrumpidos por uno de los mayores actos agresivos de la historia: el estallido de la Segunda Guerra Mundial. Dichos esfuerzos no fueron retomados sino hasta 1945, en el contexto de los históricos procesos judiciales celebrados por los Tribunales del Nüremberg y Tokio, y de la adopción de la Carta de la Organización de las Naciones Unidas (CONU).

\section{Aportaciones de los Tribunales Militares Internacionales de Nüremberg y Tokio a la identificación de los elementos del acto y crimen de agresión}

Los Tribunales Militares Internacionales de Nüremberg (TMIN) y Tokio (TMIT) fueron creados con la finalidad de juzgar a los principales criminales de guerra del eje europeo y el lejano oriente, cuyos crímenes no tuvieron una localización geográfica determinada. ${ }^{24}$ El TMIN fue

torio, todas las medidas en su poder para privar a dichas bandas de toda ayuda o protección.

24 El Consejo de Control de Alemania promulgó la Ley núm. 10 el 20 de diciembre de 1945 para dar cumplimiento a la Declaración de Moscú de 1943, al Acuerdo de Londres del 8 de agosto de 1945, y al Estatuto de Nüremberg, así como para establecer una 
creado por Estados Unidos, Unión Soviética, Reino Unido y Francia, mediante el Acuerdo de Londres del 8 de agosto de 1945. Por su parte, el TMIT fue creado el 19 de enero de 1946 a través de una Proclamación Especial del Comandante Supremo de las potencias aliadas, general Douglas McArthur, con arreglo a la Declaración de Potsdam del 26 de junio de 1945, en la cual se afirmaba que las potencias aliadas en guerra contra Japón declararon que llevar ante la justicia a los criminales de guerra sería una de las condiciones de la rendición, así como el Instrumento de Rendición de Japón del 2 de septiembre de 1945, mediante el cual dicho país aceptó tales condiciones.

Los Tribunales de Nüremberg y Tokio centraron sus trabajos en la responsabilidad penal individual de los altos mandos políticos y militares de las potencias del eje europeo y Japón. Así, el Tribunal de Nüremberg sentenció que "los crímenes contra el derecho internacional son cometidos por hombres, no por entidades abstractas y sólo castigando a las personas que cometen esos crímenes puede hacerse respetar la normativa del derecho internacional". ${ }^{25}$ Ambos tribunales aportaron algunos elementos de gran importancia para la determinación de las categorías y formas que puede revestir un acto de agresión de un Estado contra otro, así como para su plena tipificación como crimen internacional.

La mayor aportación de los tribunales fue haber proporcionado una definición de la agresión. El artículo 6o. del Estatuto del Tribunal de Nüremberg disponía: “a) Delitos contra la paz; A saber, planear, preparar, iniciar o hacer una guerra de agresión que viole tratados, acuerdos o garantías internacionales o participar en un plan común o conspiración para la perpetración de cualquiera de los actos indicados".

Por su parte, el artículo 5o. del Estatuto del Tribunal de Tokio señalaba: “a) Delitos contra la paz: A saber, planear, preparar, iniciar o hacer una guerra declarada o no declarada de agresión que viole tratados, acuerdos o garantías internacionales o participar en un plan común o conspiración para la perpetración de cualquiera de los actos indicados".

base jurídica uniforme en Alemania para el enjuiciamiento de los criminales que no integraban la nómina de los principales criminales sometidos al Tribunal de Nüremberg (es decir, aquéllos cuyos crímenes si tenían una localización geográfica determinada). Véase Documento: PCNICC/2002/WGCA/L.1, Examen histórico de la evolución en materia de agresión, p. 67. Comisión Preparatoria de la Corte Penal Internacional, Grupo de Trabajo sobre el Crimen de Agresión.

25 Sentencia de Nüremberg, p. 64. 
A las definiciones proporcionadas debemos añadir el artículo 2o. de la Ley núm. 10 del Consejo de Control de Alemania, promulgada el 20 de diciembre de 1945, en el cual se concebía a la agresión como:

a) Delitos contra la paz: Iniciar invasiones de otros países y guerras de agresión en violación de leyes y tratados internacionales, lo que incluye, entre otras cosas, planear, preparar, iniciar o hacer una guerra de agresión o una guerra que viole tratados, acuerdos o garantías internacionales o participar en un plan común o conspiración para la perpetración de cualquiera de los actos indicados.

Más allá de que los artículos anteriores tuvieran como objetivo fincar responsabilidad individual, de su redacción se desprende una condición previa que debe ser determinada antes de proceder al análisis de dicha responsabilidad, a saber: la existencia de un acto de agresión por parte del Estado involucrado. Sólo el Estado, como sujeto de derecho internacional, puede iniciar invasiones o guerras y con ello violar tratados o acuerdos internacionales. "La norma de derecho internacional que prohíbe la agresión se aplica al comportamiento de un Estado para con otro Estado. Por consiguiente, sólo el Estado puede cometer una agresión infringiendo la norma de derecho internacional que prohíbe ese comportamiento". ${ }^{26}$ El Estado es el instrumento mediante el cual los individuos llevan al cabo muchas de sus acciones en el ámbito mundial, por lo tanto, la conducta individual hace que el Estado incurra en responsabilidad internacional.

De la misma redacción de los artículos antes mencionados se deduce fácilmente que los tribunales militares utilizaron varios términos para referirse a un mismo tipo penal, es decir, no se hace alusión expresa al concepto agresión, sino que se emplearon vocablos tales como: guerra de agresión, guerra declarada o no declarada de agresión, y guerra que viole tratados, acuerdos o garantías internacionales para referirse a las diferentes categorías de agresión y guerra que fueron desarrolladas durante el segundo conflicto bélico mundial.

El manejo de términos diversos para referirse a un mismo acto también fue utilizado a lo largo de los trabajos realizados por los tribunales

26 PCNICC/2000/WGCA/INF/1, Documento de referencia sobre el crimen de agresión, preparado por la Secretaría, p. 7. 
en cuestión. Así, el TMIN calificó al ataque alemán contra la URSS como "una pura y simple agresión"; ${ }^{27}$ a la invasión de Austria como "una medida para llevar adelante el plan de hacer guerras de agresión"; 28 a la invasión de Bélgica, los Países Bajos y Luxemburgo como un "acto de guerra de agresión", ${ }^{29}$ y a la anexión de Austria como "un acto de agresión no imputado como guerra de agresión". ${ }^{30}$ Por su parte, el TMIT calificó como "guerras de agresión"31 los conflictos bélicos, declarados o no declarados, iniciados por Japón en contra de China, Francia, Estados Unidos, URSS y el commonwealth británico. ${ }^{32}$

$\mathrm{Ni}$ en los trabajos de los tribunales militares ni en su jurisprudencia aparece mención alguna sobre los alcances y significado que dichas instancias penales dieron a todos y cada uno de los términos antes mencionados. Lo que sí puede ser afirmado es que tales conceptos constituyen algunas de las principales modalidades o categorías que pueden revestir los actos de agresión de un Estado contra otro. Reviste especial importancia el término guerra declarada o no declarada de agresión, ya que pone de manifiesto la irrelevancia jurídica de dicha declaración para los efectos de eximir de responsabilidad internacional tanto al Estado como a los individuos involucrados en actos de agresión. La Comisión de Crímenes de Guerra de la ONU sostuvo que "la irrelevancia de la declaración de guerra fue la principal novedad introducida en el derecho internacional por los Estatutos de los Tribunales de Nüremberg y Tokio y por las sentencias del Tribunal de Núremberg". 33

27 PCNICC/2002/WGCA/L.I/Add.1, Examen histórico de la evolución en materia de agresión, preparado por la Secretaría. Adición, p. 4.

28 Idem.

29 Idem.

30 Idem.

31 Ibidem, p. 7.

32 Los tribunales militares creados con base en la Ley núm. 10 del Consejo de Control de Alemania identificaron a los siguientes actos como constitutivos de agresión: 1. El cambio o el intento de cambiar las relaciones internacionales mediante la fuerza de las armas (Estados Unidos c. Wilhelm von Leeb y otros (el caso Alto Mando). Ibidem, p. 5). 2. La iniciación de una guerra contra una nación vecina (Estados Unidos c. Carl Krauch y otros (el caso I. G. Farben). Idem.) 3. Una invasión hostil y agresiva es un acto de guerra tal que equivale a una declaración de guerra (Estados Unidos c. Ernst von Weizsäcker y otros (el caso Ministerios). Idem).

33 Ibidem, p. 6. 
A la anterior aportación se suma el precedente jurídico proporcionado por el Tribunal de Núremberg, relativo a que "iniciar una guerra de agresión no es sólo un crimen internacional; es el supremo crimen internacional y sólo difiere de otros crímenes de guerra en que contienen dentro de sí el mal acumulado de todos ellos". ${ }^{34}$ Afirmación de gran trascendencia ya que permite identificar al crimen de agresión como el acto inicial que rompe la paz y la seguridad internacionales, y que además, al propiciar el estallido de un conflicto bélico, genera las condiciones necesarias para que las partes en conflicto comentan otros crímenes como son los de guerra y los de lesa humanidad. Tal fue la importancia para la justicia penal internacional de esta y otras afirmaciones aportadas por el TMIN, que la Comisión de Derecho Internacional, a petición de la Asamblea General de las Naciones Unidas, recopiló y aprobó en julio de 1950 un documento titulado Principios de Derecho Internacional reconocidos por el Estatuto y por las Sentencias del Tribunal de Nuremberg, en cuyo principio VI se reconoce a los delitos contra la paz (agresión) como delitos contra el derecho internacional. Mismo reconocimiento fue realizado en los párrafos 2 y 3 del principio 1o. de la Declaración sobre los Principios de Derecho Internacional referentes a las Relaciones de Amistad y a la Cooperación entre los Estados de Conformidad con la Carta de las Naciones Unidas, adoptada mediante la resolución 2625 (XXV) de la Asamblea General del 24 de octubre de 1970.35

Con base en los precedentes aportados por los tribunales militares internacionales en materia de agresión, la ONU se dio a la tarea de presentar a los Estados diversos proyectos encaminados a que la comunidad internacional contara con una definición de la agresión.

\section{La definición del acto de agresión en el marco de la organización}

internacional. Las aportaciones de la Organización de las Naciones Unidas

Mediante la resolución 688 (VII) del 20 de diciembre de 1952, la Asamblea General (AG) estableció la Comisión Especial sobre la cuestión de la agresión (en adelante Comisión Especial), con la tarea de pre-

34 Sentencia del Tribunal de Nüremberg, p. 186.

35 El párrafo 3 del principio 1o. de dicha Declaración, afirma además que conforme a los propósitos y principios de las Naciones Unidas, los Estados tienen el deber de abstenerse de hacer propaganda en favor de las guerras de agresión. 
sentar proyectos sobre la definición de la agresión con base en los siguientes criterios: $a$ ) las diversas formas de agresión; $b$ ) la relación entre la definición de agresión y el mantenimiento de la paz y la seguridad internacionales; c) las cuestiones suscitadas por la inclusión de una definición de la agresión en el Código de Delitos contra la Paz y la Seguridad de la Humanidad y por su aplicación en la esfera de la jurisdicción penal internacional, y $d$ ) la influencia de una definición de la agresión sobre el ejercicio de la competencia constitucional de los órganos de las Naciones Unidas.

El debate en torno a la agresión propició el surgimiento de tres corrientes o posturas teóricas, a saber: 1. la de los que querían buscar una definición casuística, enumerando todos y cada uno de los posibles actos de agresión; 2. los que sostenían que era más conveniente una definición general y abstracta, en la que pudieran englobarse las nuevas modalidades de agresión, que no era posible prever en la enumeración casuística, y 3. la posición ecléctica, según la cual lo mejor sería combinar las dos anteriores, y terminar con una fórmula que permitiera la inclusión de las agresiones no previstas. Finalmente, existía una cuarta postura que defendía que lo mejor sería no tener definición alguna de agresión, sino que un órgano internacional adecuado se encargara en cada situación de determinar si existía o no. ${ }^{36}$ Esta última postura fue descartada por las Naciones Unidas en razón de que era imperiosa la necesidad de contar con una definición de la agresión que facilitara la determinación del acto y sus consecuencias jurídicas.

El trabajo de la Comisión Especial estuvo fuertemente influenciado por las tres corrientes antes mencionadas, de ahí que el proyecto final presentado a la AG haya propuesto una definición ecléctica o mixta. El 14 de diciembre de 1974 la AG adoptó la resolución 3314 (XXIX) relativa a la definición de la agresión, cuyo objetivo principal fue proporcionar al CS una definición del acto en cuestión que le sirviera de orientación al momento de determinar la existencia de agresiones.

En el artículo 1o. de la resolución 3314 (XXI) se define a la agresión como: "El uso de la fuerza armada por un Estado contra la soberanía, la integridad territorial o la independencia política de otro Estado, o en

36 Cfr. Seara Vázquez, Modesto, Derecho internacional público, 14a. ed., México, Porrúa, 1993, p. 395. 
cualquier otra forma incompatible con la Carta de las Naciones Unidas". 37

Dicha disposición debe interpretarse de manera conjunta con el artículo 3o., en el cual se dispone que:

cualquiera de los actos siguientes, independientemente de que haya o no declaración de guerra, se caracterizará como acto de agresión:

a) La invasión o el ataque por las fuerzas armadas de un Estado, del territorio de otro Estado, o toda ocupación militar, aún temporal, que resulte de dicha invasión o ataque, o toda anexión mediante el uso de la fuerza, del territorio de otro Estado o de parte de él;

b) El bombardeo, por las fuerzas armadas de un Estado, del territorio de otro Estado, o el empleo de cuales quiera armas por un Estado, contra el territorio de otro Estado;

c) El bloqueo de los puertos o de las costas de un Estado por las fuerzas armadas de otro Estado;

d) El ataque de las fuerzas armadas de un Estado contra las fuerzas armadas terrestres, navales o aéreas de otro Estado, contra su flota mercante o aérea;

e) La utilización de fuerzas armadas de un Estado, que se encuentran en el territorio de otro Estado con el acuerdo del Estado receptor, en violación de las condiciones establecidas en el acuerdo, o toda prolongación de su presencia en dicho territorio después de terminado el acuerdo;

f) La acción de un Estado que permite que su territorio, que ha puesto a disposición de otro Estado, sea utilizado por otro Estado para perpetrar un acto de agresión contra un tercer Estado;

g) El envío por un Estado, o en su nombre, de bandas, grupos irregulares o mercenarios que lleven a cabo actos de fuerza armada contra otro Estado, de tal gravedad, que sean equiparables a los actos antes enumerados, o su substancial participación en dichos actos.

Por su parte, el artículo 2o. señala que:

El primer uso de la fuerza armada por un Estado en contravención de la Carta constituirá prueba prima facie de un acto de agresión, aunque el Consejo de Seguridad puede concluir, de conformidad con la Carta, que la

37 El artículo 1o. se complementa con la siguiente nota explicativa: En esta definición el término "Estado": a) Se utiliza sin perjuicio de las cuestiones de reconocimiento o de que un Estado sea o no miembro de las Naciones Unidas; b) Incluye el concepto de un "grupo de Estados", cuando proceda. 
determinación de que se ha cometido un acto de agresión no estaría justificada a la luz de otras circunstancias pertinentes, incluido el hecho de que los actos de que se trata o sus consecuencias no son de suficiente gravedad.

Las disposiciones de los artículos 10., 20. y 3o. se complementan con los párrafos 2 y 3 del artículo 5o., que a la letra dicen: "2. la guerra de agresión es un crimen contra la paz internacional. La agresión origina responsabilidad internacional; 3 . ninguna adquisición territorial o ventaja especial resultante de una agresión es lícita ni será reconocida como tal”.

El artículo 1o. incorpora una definición genérica o abstracta de la agresión. Con base en ella, se pueden establecer las principales características de dicho acto, a saber:

a) la noción de agresión viene limitada al uso de la fuerza armada, b) la noción de agresión se aplica única y exclusivamente a las relaciones entre Estados y, por consiguiente, el uso de la fuerza armada en el interior de un Estado no entra en el área de esta definición, y c) el texto guarda silencio sobre la amenaza de la fuerza armada y tal circunstancia no permite considerar la referida amenaza como agresión. ${ }^{38}$

La definición proporcionada deja sin efecto la fórmula contemplada en el artículo 10 del PSN (la amenaza de agresión como acto de agresión), limitándola a la ocurrencia de hechos consumados; requisito que se confirma en el artículo 2o., al establecerse que el primer uso de la fuerza armada es prueba prima facie de un acto de agresión.

La decisión de eliminar el término amenaza del uso de la fuerza o de agresión de la definición adoptada fue sumamente atinada, ya que dicho término pudo prestarse a interpretaciones ambiguas a fin de justificar el uso de la fuerza en situaciones determinadas. Además, ante un acto de agresión consumado el derecho de gentes permite el recurso a la legítima defensa y al uso de la fuerza armada como parte de las medidas dictadas por el CS. No existe norma de derecho internacional consuetudinario o convencional que permita el uso de la fuerza armada ante amenazas a la paz; en tales circunstancias se cuenta con el tiempo suficiente para recurrir a los mecanismos de solución pacífica de controversias o al propio CS para que indique medidas no coercitivas a fin de garantizar la paz y la seguridad internacionales. Sólo el propio Consejo puede autorizar el uso 
de la fuerza armada ante situaciones de amenaza, siempre y cuando, las acciones no coercitivas previamente indicadas hayan mostrado ser ineficaces.

Para François Bugnion, "en la resolución 3314 se toma en cuenta un elemento esencialmente subjetivo, el motivo del recurso a las armas, que es incompatible con una verdadera definición, puesto que una definición capaz de provocar efectos jurídicos debe fundarse en elementos objetivos y verificables". ${ }^{39}$ Del comentario anterior se podría desprender que la responsabilidad internacional prevista en el artículo 5o., párrafo 2, deja de lado la teoría de la responsabilidad objetiva, al no identificar al daño y al nexo causal entre el responsable y el afectado como prueba de responsabilidad, sino que, por el contrario, atribuye demasiada importancia al elemento subjetivo en la violación de la norma internacional, es decir, la agresión como medio de atentar contra la supervivencia de algún Estado, lo que se reduce a una invocación de la teoría de la falta.

La responsabilidad internacional contemplada en la resolución 3314 (XXIX) no otorga un papel central al elemento subjetivo en la determinación del acto de agresión. El elemento subjetivo relativo a los motivos del recurso a las armas perdió importancia a partir del momento en que el uso de la fuerza fue prohibido en las relaciones internacionales. Así, la responsabilidad contemplada en el artículo 5o., párrafo 2, es objetiva debido a que requiere la existencia de un daño (ataque armado), un nexo causal entre el agredido y el agresor, así como la violación de una norma jurídica internacional (prohibición de la agresión).

Además, el jurista Antonio Remiro Brotóns sostiene que:

un acto de agresión genera necesariamente la responsabilidad internacional del Estado agresor. Es ésta una responsabilidad acentuada en la medida en que, tratándose de violación grave de una obligación emanada de norma imperativa del Derecho Internacional, su ilicitud no puede ser excluida por ninguna circunstancia ni pueden aceptarse sus consecuencias. ${ }^{40}$

39 Bugnion, François, "Guerra justa, guerra de agresión y derecho internacional humanitario”, Revista Internacional de la Cruz Roja, Ginebra, núm. 847, 2002, p. 14.

40 Remiro Brotóns, Antonio, Agresión, crimen de agresión, crimen sin castigo, Documento de trabajo, Madrid, Fundación para las Relaciones Internacionales y el Diálogo Exterior (FRIDE), 2005, p. 5. Este trabajo también puede consultarse en $h t t p: / / w w w . p o l i$ ticaexterior.com. 
La reflexión del profesor Remiro Brotóns introduce un elemento de gran importancia a la discusión: la imposibilidad de aceptar las consecuencias de un acto agresivo, elemento que forzosamente nos remite al párrafo tercero del artículo 5o. de la resolución 3314, en el que se señala que ninguna adquisición territorial o ventaja especial producto de una agresión es lícita ni será reconocida; esto es, se reconoce el principio $E x$ injuria ius non oritur, es decir, que el acto ilícito no genera derechos.

Ahora bien, el artículo 3o. de la resolución 3314 complementa la definición genérica con un listado de actos, que por su gravedad serán considerados como agresión. En torno al artículo 3o. se han vertido los siguientes comentarios: por un lado, se celebra la incorporación de los incisos "f" y "g" que aluden a la denominada agresión indirecta, y, por otro lado, los que señalan que dicho artículo sólo presenta "una lista (incompleta) de las acciones que están prohibidas por el derecho internacional y que son las formas más serias y peligrosas del ilegal uso de la fuerza" ${ }^{41}$ y "que nada dice prácticamente acerca de las formas de agresión indirecta que caracterizan a nuestra época, como la subversión, los atentados terroristas, la injerencia extranjera en caso de guerra civil, etcétera". ${ }^{42}$

Es un hecho que el listado presentado es incompleto y sólo prevé las manifestaciones más graves del uso de la fuerza conocidas en la época en que fue adoptada la resolución. Sin embargo, el problema no es el listado, sino la fórmula adoptada en el artículo 4o. para que otros actos puedan ser considerados como agresivos. Dicho artículo señala que: "La enumeración de los actos mencionados anteriormente no es exhaustiva y el Consejo de Seguridad podrá determinar qué otros actos constituyen agresión, con arreglo a las disposiciones de la Carta".

El mencionado artículo otorga a un órgano político la capacidad para determinar otras situaciones constitutivas de agresión. La historia y el quehacer del CS en la determinación de actos de agresión han sido ambivalentes y estrechamente vinculados a los intereses políticos de sus miembros permanentes. A diferencia del artículo 1o., donde no encontramos un elemento subjetivo en la determinación de actos de agresión, en el artículo 4o. sí aparece tal elemento configurado en la facultad atribuida al Consejo. Sin embargo, dicha atribución no es la única, ya que el ar- 
tículo 2o. capacita al CS para determinar la inexistencia de agresiones con base en circunstancias pertinentes y en la gravedad de las consecuencias de los pretendidos actos de agresión. La resolución 3314 jamás menciona qué debe entenderse por circunstancias pertinentes o consecuencias suficientemente graves. Es más, ni siquiera hace mención a la magnitud que debe tener el uso de la fuerza armada para ser considerada como agresión. Lo que sí queda claro es que se otorga al Consejo una facultad preclusiva tanto en la determinación de agresiones como en la de sus consecuencias.

Las atribuciones concedidas al CS en los artículos 2o. y 4o. de la resolución 3314 (XXIX), y que tienen su fundamento en las responsabilidades conferidas a dicho órgano político en los artículos 24 y 39 de la Carta de la ONU, han propiciado un amplio y polémico debate en torno a la competencia que detentan otros órganos de la ONU, en particular la Asamblea General y la Corte Internacional de Justicia, en materia de agresión. En el siguiente apartado analizaremos a profundidad esta problemática.

\section{El debate en torno a la pretendida facultad exclusiva del Consejo de Seguridad para determinar la existencia de actos de agresión}

Durante la redacción de la CONU, las potencias vencedoras de la Segunda Guerra Mundial, tuvieron el cuidado de asegurarse el monopolio del uso legítimo de la fuerza, la capacidad para determinar las situaciones de amenaza y quebrantamientos a la paz y actos de agresión, y de que sus resoluciones fueran las únicas con carácter vinculante de todas las emitidas por la nueva organización internacional, mediante su posición como miembros permanentes en el CS. Así, el artículo 24 de la Carta establece a la letra que:

A fin de asegurar acción rápida y eficaz por parte de las Naciones Unidas, sus Miembros confieren al Consejo de Seguridad la responsabilidad primordial de mantener la paz y la seguridad internacionales, y reconocen que el Consejo de Seguridad actúa en nombre de ellos al desempeñar las funciones que le impone aquella responsabilidad.

Por su parte, el artículo 39 dispone que: "El Consejo de Seguridad determinará la existencia de toda amenaza a la paz, quebrantamiento de la paz o acto de agresión y hará recomendaciones o decidirá qué medidas 
serán tomadas de conformidad con los artículos 41 y 42 para mantener o restablecer la paz y la seguridad internacionales".

Los artículos antes mencionados se encuentran estrechamente vinculados, ya que el CS tiene la facultad de determinar, entre otras situaciones, la existencia de actos de agresión, en la medida en que es el órgano de la ONU encargado de actuar de manera rápida y eficaz en el mantenimiento o restablecimiento de la paz y seguridad internacionales. Es decir, se establece que el CS, a través de sus medidas coercitivas o no coercitivas, es el órgano de reacción inmediata de la ONU, pero en ningún momento se señala que sea el único.

En efecto, el artículo 11, párrafos 2 y 3 , señala que la AG podrá:

discutir toda cuestión relativa al mantenimiento de la paz y la seguridad internacionales que presente a su consideración cualquier Miembro de las Naciones Unidas o el Consejo de Seguridad, o que un Estado que no es Miembro de las Naciones Unidas presente..., y salvo lo dispuesto en el artículo 12, podrá hacer recomendaciones acerca de tales cuestiones al Estado o Estados interesados o al Consejo de Seguridad o a éste y a aquéllos. 3. La Asamblea General podrá llamar la atención del Consejo de Seguridad hacia situaciones susceptibles de poner en peligro la paz y la seguridad internacionales.

Esta disposición se complementa con el texto del artículo 14, en el cual se establece que: "Salvo lo dispuesto en el artículo 12, la Asamblea General podrá recomendar medidas para el arreglo pacífico de cualesquiera situaciones... que a juicio de la Asamblea puedan perjudicar el bienestar general o las relaciones amistosas entre naciones".

La excepción contemplada en el artículo 12 señala expresamente que: "mientras el Consejo de Seguridad esté desempeñando las funciones que le asigna esta Carta con respecto a una controversia o situación, la Asamblea General no hará recomendación alguna sobre tal controversia o situación, a no ser que lo solicite el Consejo de Seguridad".

La CONU no contempla que la AG debe abstenerse de conocer sobre asuntos relativos a la paz y la seguridad internacionales, sino más bien establece un sistema jerárquico de competencias y complementario entre los dos principales órganos políticos de la ONU. Jerárquico porque el CS es el órgano encargado de la paz y la seguridad; complementario porque la AG puede llamar la atención del CS ante situaciones que pueden poner en peligro la estabilidad del sistema internacional, y porque también pue- 
de hacer recomendaciones cuando el CS no esté atendiendo dichas amenazas o en los casos en que el propio Consejo se lo solicite. Esta aseveración fue confirmada en el contexto de la guerra de Corea (1950-1953), en la que el CS se vio paralizado por la falta de acuerdo entre sus miembros permanentes para adoptar medidas encaminadas a restablecer la paz y la seguridad internacionales, por medio de la resolución 377 (V) sobre "Unión pro Paz" adoptada por la AG el 3 de noviembre de 1950, en la cual se indicó que:

Si el Consejo de Seguridad, por falta de unanimidad de sus miembros permanentes, dejara de cumplir con su responsabilidad primordial por el mantenimiento de la paz y la seguridad internacionales en todo caso en que resultara haber una amenaza a la paz, un quebrantamiento de la paz o un acto de agresión, la Asamblea General examinaría inmediatamente el asunto, con miras a dirigir a los Miembros recomendaciones apropiadas para la adopción de medidas colectivas, inclusive, en caso de quebrantamiento de paz o acto de agresión, el uso de fuerzas armadas cuando fuere necesario, a fin de mantener o restaurar la paz y la seguridad internacionales. ${ }^{43}$

Posición similar a la anterior asumió la CIJ en su opinión consultiva de 1962, relativa a Ciertos gastos de las Naciones Unidas, en la que el máximo órgano judicial de las Naciones Unidas afirmó que "la responsabilidad conferida al Consejo de Seguridad por el artículo 24 de la Carta es 'primordial', pero no exclusiva". ${ }^{44}$ Asimismo, la Corte señaló que:

La Carta deja abundantemente en claro, que la Asamblea General ha de ocuparse también de la paz y la seguridad internacionales. El artículo 14 autoriza a la AG a recomendar 'medidas' para el arreglo pacífico de cualesquiera situaciones que puedan poner en riesgo las relaciones amistosas entre naciones. De acuerdo con la CIJ, la palabra medidas denota cierto tipo de acción, y la única limitación que el artículo 14 impone a la Asamblea General es la restricción que figura en el artículo 12..., Así pues, mientras el Consejo de Seguridad es quien, exclusivamente puede ordenar medidas coercitivas, las funciones y poderes conferidos por la Carta a la Asamblea General no están limitados a la discusión, la consideración, la ini-

43 Parte A, párrafo 1 de la resolución 377 (V).

44 Opinión consultiva de la Corte Internacional de Justicia relativa a "Ciertos gastos de las Naciones Unidas”, pronunciada el 20 de julio de 1962. I.C.J., Reports, 1962, p. 163. 
ciación de estudios y la formulación de recomendaciones. El artículo 18 se refiere a las 'decisiones' de la Asamblea General en cuestiones importantes. Tales decisiones comprenden efectivamente determinadas recomendaciones, pero otras tienen fuerza y efectos dispositivos. Entre estas últimas decisiones, el artículo 18 menciona la suspensión de los derechos y privilegios de los Miembros, la expulsión de Miembros, y las cuestiones presupuestarias. ${ }^{45}$

Las competencias en materia de paz y seguridad internacionales conferidas al CS y a la AG en la CONU son complementarias, independientemente, de que los miembros permanentes del CS intenten arrogarse facultades exclusivas. Sería absurdo pensar que la ONU y la paz y seguridad internacionales podrían verse paralizadas debido a la falta de acuerdo entre los miembros del CS. Mientras que la práctica del CS en la materia ha dejado mucho que desear debido a los intereses políticos defendidos por sus miembros más conspicuos, la AG ha sabido conciliar posiciones e intereses políticos en pro de la paz internacional.

Una vez aclarado el tema relativo a las competencias de los órganos políticos de las Naciones Unidas en materia de agresión, debemos proceder a revisar las competencias de la CIJ en el mismo ámbito y con respecto a las facultades del CS. Las relaciones entre el CS y la CIJ en materia de paz y seguridad, uso de la fuerza y agresión, han sido por demás ambivalentes, y se ha pretendido establecer la superioridad del Consejo sobre la Corte, generando con esto un amplio debate en torno a los verdaderos alcances de las facultades otorgadas a cada uno de estos órganos.

En 1979, tras el triunfo de la Revolución Islámica en Irán y la toma de la embajada de Estados Unidos en Teherán por parte de simpatizantes del régimen del Ayatollah Jomeini, el CS adoptó medidas encaminadas a conseguir la liberación del personal diplomático y consular estadounidense retenido en los locales diplomáticos tomados. Ante el fracaso de estas medidas, Estado Unidos recurrió a la CIJ para solicitar la indicación de medidas provisionales al gobierno iraní tendientes a devolver los locales tomados, la liberación de los nacionales estadounidenses, a asegurar el respeto de los privilegios e inmunidades del personal diplomático y consular de Estados Unidos, y a no tomar ninguna medida que pu- 
diera agudizar la tensión entre los dos países en disputa. El 15 de diciembre de 1979 la Corte dictó por unanimidad la providencia solicitada.

Durante el análisis del fondo del asunto relativo al Personal diplomático y consular de los Estados Unidos en Teherán, la CIJ tuvo que revisar sus facultades para poder tratar el asunto planteado, ya que el CS estaba ocupándose simultáneamente del mismo asunto. La Corte llegó a la conclusión de que "el Consejo de Seguridad, en su reunión del 31 de diciembre de 1979, tomó nota de la providencia de la Corte, y no parece que se la haya ocurrido a ninguno de los miembros del Consejo que había o podía haber algo irregular en el ejercicio simultáneo de sus respectivas funciones por parte de la Corte y el Consejo de Seguridad". 46 Además, la Corte indicó que no había nada irregular en el ejercicio simultáneo de sus respectivas funciones, ya que:

En tanto que en el artículo 12 de la Carta se prohíbe expresamente a la Asamblea General hacer recomendación alguna sobre una controversia o situación mientras el Consejo de Seguridad esté desempeñando sus funciones con respecto a tal controversia o situación, ninguna disposición de la Carta o el Estatuto de la Corte establece una restricción de esa índole en lo tocante al funcionamiento de la Corte. Las razones son claras. Incumbe a la Corte... resolver las cuestiones jurídicas de cualquier tipo respecto de las cuales se contrapongan las partes en una controversia. ${ }^{47}$

La postura asumida por la Corte fue bien recibida por Estados Unidos y los miembros del CS, toda vez que la solución judicial de la controversia entre Estados Unidos e Irán se había convertido en la única solución posible tras haberse comprobado la ineficacia de las medidas adoptadas por el Consejo y el fracaso de la incursión militar realizada por Estados Unidos en Irán. Caso contrario aconteció en 1984, cuando Nicaragua presentó ante la CIJ una demanda en contra de Estados Unidos por la realización de este último país de actividades militares y paramilitares en y contra su territorio y soberanía.

En dicho asunto, Estados Unidos argumentó, a fin de establecer la falta de competencia de la Corte para conocer del caso, que Nicaragua

46 Sentencia de la Corte Internacional de Justicia en el asunto relativo al "Personal diplomático y consular de los Estados Unidos en Teherán”, I.C.J., Reports, 1980, del 24 de mayo de 1980, p. 21.

47 Ibidem, p. 22. 
había formulado una imputación de agresión y conflicto armado prevista en el artículo 39 de la CONU, de la que sólo podía ocuparse el CS con arreglo a las disposiciones del capítulo VII de la carta, y no con arreglo a las del capítulo VI en las que se prevé la actuación de la Corte. Además, señaló que el demandante estaba ocupando a la Corte como una instancia de apelación de las decisiones del CS, ante la negativa de este órgano por adoptar medidas encaminadas a satisfacer las demandas nicaragüenses. La Corte rechazó los argumentos estadounidenses con base en los siguientes razonamientos:

Primero, la Corte no había recibido notificación alguna del CS en la cual se le pidiera aplazar el examen completo de la cuestión de fondo hasta que tanto se tomara la decisión de autorizar las medidas coercitivas necesarias. ${ }^{48}$ Segundo, y haciendo referencia al asunto del Personal diplomático y consular de los Estados Unidos en Teherán, expresó que "la opinión de que el hecho de que un asunto se encuentre ante el Consejo de Seguridad no debería impedir que la corte se ocupara de él y que ambos procedimientos podían seguir adelante pari passu". ${ }^{49}$ Tercero, la Corte sostuvo nuevamente que "la Carta no confiere al Consejo de Seguridad una responsabilidad exclusiva [en materia de paz y seguridad]". ${ }^{50} \mathrm{El}$ artículo 12 prevé una clara demarcación entre las funciones del CS y la AG, pero en ninguna disposición de la carta existe una disposición análoga con respecto al CS y a la CIJ. "Al Consejo se le han asignado funciones de naturaleza política, mientras que la corte ejerce funciones puramente judiciales. Por consiguiente, ambos órganos pueden desempeñar sus funciones separadas pero complementarias con respecto a los mismos acontecimientos". ${ }^{51} \mathrm{Y}$ cuarto, en cuanto a la cuestión referente a la utilización de la Corte como una instancia de apelación de las decisiones del Consejo, el máximo órgano judicial señalo que:

No se pide a la Corte que diga que el Consejo de Seguridad adoptó una decisión errada, ni que hubo algo incompatible con el derecho en la forma en que los miembros del Consejo emplearon su derecho de voto. Se pide a la Corte que juzgue respecto de algunos aspectos jurídicos de una situación que también ha sido considerada por el Consejo de Seguridad, un

48 Op. cit., nota 19, p. 434.

49 Ibidem, p. 433.

$50 \quad$ Ibidem, pp. 434 y 435.

51 Idem. 
procedimiento que es totalmente compatible con su posición de órgano judicial. ${ }^{52}$

De manera por demás atinada, la CIJ dejó en claro su competencia para analizar y fallar asuntos relacionados con la paz y la seguridad internacionales de manera simultánea a su examen en el CS. La única limitante a esta capacidad se encuentra en la posibilidad de que el CS le solicite, de manera expresa y a través de una resolución, aplazar el examen completo de la cuestión que le ha sido presentada. En ningún momento la Corte invade las competencias del CS, ya que este último determina las situaciones de amenaza y quebrantamiento de la paz o actos de agresión, a fin de adoptar medidas inmediatas para garantizar la paz y seguridad. Por su parte, la Corte tiene la capacidad para determinar las consecuencias jurídicas de los actos en cuestión, es decir, determinar la responsabilidad internacional del Estado infractor, así como las modalidades, con base en los hechos dados, en que deberán ser reparados los daños ocasionados. La determinación hecha por el consejo está basada en criterios eminentemente políticos, mientras que la realizada por la Corte se fundamento en razonamientos jurídicos. Una vez más, y como en el caso de la relación entre el CS y la AG, las funciones de la CIJ y el CS en materia de paz y seguridad son complementarias.

El debate en torno a las facultades del CS en la determinación de actos de agresión fue retomado en los trabajos preparatorios de la Conferencia de Roma del 17 de julio de 1998 en la cual se adoptó el Estatuto de la Corte Penal Internacional (CPI), y en el que se contempla la competencia de la Corte para perseguir y sancionar a los responsables individuales del crimen de agresión. No obstante lo anterior, la falta de acuerdo entre los Estados participantes en los trabajos preparatorios de la CPI acerca de una definición del crimen de agresión y de las condiciones en que la CPI ejercería su competencia sobre dicho crimen, ocasionaron que el crimen en cuestión se viniera abajo del estatuto, y se dejará su negociación para fechas posteriores. En el siguiente apartado nos adentraremos en el estudio y revisión del quehacer realizado por el grupo de trabajo sobre el Crimen de Agresión de la Comisión Preparatoria de la CPI, para que la principal instancia penal internacional permanente cuente con 
una definición del crimen de agresión y pueda ejercer jurisdicción sobre el mismo.

\section{LA DEFINICIÓN DEL CRIMEN DE AGRESIÓN. UN ASUNTO PENDIENTE EN LA AGENDA JURÍDICO-POLÍTICA DE LAS RELACIONES INTERNACIONALES}

La adopción del Estatuto de la Corte Penal Internacional (en adelante ECPI o Estatuto de Roma) constituye el máximo logro de la sociedad civil internacional por evitar la impunidad de que gozan muchos criminales internacionales. La Corte Penal Internacional (CPI) es la única instancia penal internacional de carácter permanente competente para perseguir y sancionar a los responsables de graves crímenes contra el derecho internacional, tales como: el genocidio, los crímenes de lesa humanidad, los crímenes de guerra y el crimen de agresión (artículo 5o., párrafo 1, del ECPI). Sin embargo, dos días antes de la adopción del Estatuto de Roma, es decir el 15 de julio de 1998, la competencia de la corte sobre el crimen de agresión se vino abajo debido a la falta de acuerdo entre los Estados participantes para adoptar una definición unánime en torno a dicho crimen. Por tal motivo, el párrafo 2 del artículo quinto del ECPI se limitó a señalar que la Corte ejercerá competencia sobre el crimen de agresión una vez que se apruebe una disposición en que se defina el crimen y se enuncien las condiciones en las cuáles lo hará. Advirtiendo que tal disposición deberá ser compatible con las disposiciones pertinentes de la Carta de las Naciones Unidas (CONU). Por el momento, la CPI sólo ejerce una competencia de principio sobre dicho crimen.

Sin duda alguna, los Estados en favor del establecimiento de la CPI prefirieron dejar la discusión sobre el crimen de agresión para después, en lugar de asumir una postura inflexible que hubiera ocasionado que la adopción del estatuto se pospusiera de manera indefinida. A raíz de este desacuerdo, la Conferencia Diplomática de Plenipotenciarios de las Naciones Unidas sobre el establecimiento de una Corte Penal Internacional decidió, mediante la resolución $F$ anexa al acta final de la conferencia, crear una Comisión Preparatoria de la Corte Penal Internacional (PrepCom, por sus siglas en inglés) con la tarea de:

Preparar propuestas acerca de una disposición relativa a la agresión, inclusive la definición y los elementos del crimen de agresión y a las condicio- 
nes en las cuales la Corte Penal Internacional ejercerá su competencia sobre ese crimen. La Comisión presentará esas propuestas a la Asamblea de los Estados Partes en una Conferencia de Revisión con miras a llegar a una disposición aceptable acerca del crimen de agresión.

Desde 1999, la PrepCom, a través del Grupo de trabajo sobre el crimen de agresión (WGCA por sus siglas en inglés o GTCA por sus siglas en español), ha venido realizando un arduo trabajo formal (sesiones ordinarias) e informal (reuniones de trabajo en prestigiadas universidades del mundo) de recopilación, análisis, síntesis y conciliación de las diferentes propuestas de definición del crimen de agresión presentadas por los Estados y el propio GTCA, a fin de que la CPI pueda contar con una disposición relativa al crimen en cuestión a más tardar en 2009, fecha en que se cumplen los siete años marcados por el Estatuto de Roma para que los Estados puedan presentar enmiendas al mismo, o solicitar su revisión.

En nueve años de labor (1999-2008), los avances conseguidos por la PrepCom y el GTCA han sido relativamente escasos debido a la falta de voluntad de los Estados para flexibilizar sus posturas políticas y trabajar de manera conjunta en la elaboración de una definición del crimen de agresión y en las condiciones en las cuáles deberá ejercer su competencia la corte sobre dicho crimen. Dos son los principales puntos de desacuerdo en torno al crimen de agresión en el Estatuto de Roma: 1. la definición del crimen, y 2. la competencia del Consejo de Seguridad de las Naciones Unidas en la determinación de actos de agresión.

\section{La definición del crimen de agresión}

A diferencia de los estatutos de los Tribunales de Nüremberg y Tokio en los que el crimen en cuestión fue fácilmente definido ya que el propósito fundamental de las cuatro potencias vencedoras de la Segunda Guerra Mundial era sancionar a los vencidos, la PrepCom se enfrenta a un sistema internacional completamente divido en torno a la cuestión de la agresión, y en el que los juzgadores de antaño temen ser llevados ante la justicia por sus acciones actuales. Por esta razón, los trabajos de la Conferencia Diplomática para el establecimiento de una CPI estuvieron fuertemente influenciados por dos grandes posiciones políticas referentes a la viabilidad de introducir una disposición en materia de agresión en el Estatuto de Roma. 
Por un lado, se encontraban los Estados que apoyaban la introducción de una disposición relativa al crimen de agresión en el ECPI con base en la gravedad del crimen en cuestión y a los efectos disuasivos que generaría la adopción de una disposición en el Estatuto. Por otro lado, los que estaban en contra, y que defendían su postura sustentándose en las dificultades para definir el crimen en cuestión, a su naturaleza altamente política, al riesgo de que una disposición en la materia pudiera ser utilizada con fines políticos, y a la vinculación estrecha que guarda el crimen de agresión con los crímenes de guerra.

El crimen de agresión no podía quedar fuera de la competencia de la Corte debido a su gravedad y serías consecuencias para la paz y seguridad internacionales. La agresión es el crimen supremo del derecho internacional, es el acto que permite que se perpetren otros crímenes (de guerra, lesa humanidad y genocidio); por tal motivo, es ilógico pensar que la CPI pueda sancionar a los responsables de los crímenes cometidos al amparo de una agresión, pero no a los individuos que con su accionar crearon las condiciones propicias para que dichos crímenes fueran cometidos.

A lo largo de sus nueve años de trabajo, la PrepCom ha insistido a los Estados en que la definición del crimen de agresión debe contemplar tres grandes elementos: A. el requisito de liderazgo, B. la conducta individual, y C. el acto estatal de agresión.

\section{A. El requisito de liderazgo}

El GTCA ha acordado que "el crimen de agresión es un crimen de liderazgo". ${ }^{53}$ Dicha identificación fue realizada por primera vez por el Tribunal de Nüremberg al señalar que:

los acusados habían utilizado sus puestos en el Partido Nazi, el Gobierno (incluidos los puestos relacionados con territorios ocupados), las fuerzas militares y paramilitares, la economía (incluidas la banca y las finanzas), la industria o los medios de comunicación; su influencia personal, y, en varios casos, su relación con el Führer para cometer los diversos crímenes que se les imputaban. ${ }^{54}$

53 Coalition for the Internacional Criminal Court, The International Criminal Court and the Crimen of Aggression, La Haya, 2007, p. 2.

54 PCNICC/2002/WGCA/L.1. Examen histórico de la evolución en materia de agresión, preparado por la Secretaría, p. 21. 
El acto de agresión es el ejemplo más representativo del uso ilegal de la fuerza armada de un Estado contra otro. El Estado es el agresor, empero a su interior sólo unas cuantas personas tienen la capacidad política para ordenar el despliegue de las fuerzas armadas en contra de otro Estado, por tal motivo, el crimen de agresión únicamente puede ser iniciado u ordenado por los jefes de Estado o de gobierno y los superiores militares facultados para movilizar a la fuerzas armadas de un Estado. Sin embargo, en la planificación y preparación de dicho acto pueden intervenir otros líderes jerárquicos tales como los empresarios, los miembros del cuerpo diplomático, los líderes religiosos, y un buen número de funcionarios de alto nivel. Dicho razonamiento fue postulado por el Tribunal de Nüremberg al sostener que: "Hitler no podía por sí solo formular una política de guerra de agresión y ejecutar por sí solo esa política preparando, planificando y llevando a cabo tal guerra. Necesitaba la colaboración de estadistas, jefes militares, diplomáticos, financieros". ${ }^{55}$

El requisito de liderazgo también fue incorporado en el Proyecto de Código de Crímenes contra la Paz y la Seguridad de la Humanidad elaborado por la Comisión de Derecho Internacional de las Naciones Unidas, cuyo artículo 16 disponía que comete el crimen de agresión: "El que, en cuanto dirigente $u$ organizador, participe activamente en la planificación, preparación, desencadenamiento o libramiento de una guerra de agresión cometida por un Estado, u ordene estas acciones, será responsable de un crimen de agresión".

Debido a la aceptación y reconocimiento internacional de que ha sido objeto el requisito de liderazgo, los Estados participantes en los trabajos de la PrepCom no han puesto ninguna traba para que el mismo aparezca en la definición del crimen de agresión.

\section{B. La conducta individual}

El artículo 25, párrafo 3, del ECPI ${ }^{56}$ establece las formas de participación susceptibles de generar la responsabilidad penal de un individuo

55 Sentencia de Nüremberg, p. 55.

56 El artículo 25, párrafo 3, del ECPI, establece que: de conformidad con el presente Estatuto, será penalmente responsable y podrá ser penado por la comisión de un crimen de la competencia de la Corte quien: a) Cometa ese crimen por sí solo, con otro o por conducto de otro, sea éste o no penalmente responsable; b) Ordene, proponga o induzca la comisión de ese crimen, ya sea consumado o en grado de tentativa; c) Con el propósito 
en la comisión o tentativa de comisión de algunos de los crímenes contemplados en el artículo 5o. del Estatuto. La PrepCom ha puesto sobre la mesa de debate la discusión relativa a si el crimen de agresión debe ceñirse a tales formas de participación (enfoque diferenciado) o si las formas de participación deben ser las contempladas en la definición del crimen de agresión (enfoque monístico) incorporadas en diversos instrumentos jurídicos internacionales, y que han sido retomadas por la mayoría de los Estados en sus propuestas presentadas a la PrepCom.

De optarse por el enfoque diferenciado, se eliminarían de la definición final del crimen las conductas individuales catalogadas como agresivas, a fin de que las mismas sean determinadas con base en el artículo 25, párrafo 3, del ECPI. De adoptarse el enfoque monístico, la definición final del crimen seguiría contemplando a la planeación, preparación, iniciación o ejecución de un acto estatal de agresión como las conductas generadoras de la responsabilidad penal individual y, por tal motivo, el mencionado párrafo tercero del artículo 25 no tendría efecto sobre la determinación de dicha responsabilidad.

El problema de fondo en cuanto a la determinación de las conductas catalogadas como agresivas previstas en el párrafo 3 radica en el desacuerdo existente entre los Estados para ubicar a la tentativa de cometer agresión como un acto susceptible de engendrar la responsabilidad penal individual, ya que el crimen no fue consumado y por tanto no se produjo un conflicto armado. Actualmente, no se ha llegado a un consenso sobre el tema, pero todo parece indicar que la mayoría de los Estados están de acuerdo con que se excluya a la tentativa como acto de agresión.

Tampoco ha habido acuerdo para optar por alguno de los dos enfoques en pugna, sin embargo, todo señala que se está empezando a conformar una tendencia favorable de parte de los Estados hacia la adopción

de facilitar la comisión de ese crimen, sea cómplice o encubridor o colabore de algún modo en la comisión o tentativa de comisión del crimen, incluso suministrando los medios para su comisión; d) Contribuya de algún otro modo en la comisión o tentativa de comisión del crimen por un grupo de personas que tengan una finalidad común...; e) Respecto del crimen de genocidio, haga una instigación directa y pública a que se cometa, y f) Intente cometer ese crimen mediante actos que supongan un paso importante para su ejecución, aunque el crimen no se consume debido a circunstancias ajenas a su voluntad. Sin embargo, quien desista de la comisión del crimen o impida de otra forma que se consume no podrá ser penado de conformidad con el presente Estatuto por la tentativa si renunciare íntegra y voluntariamente al propósito delictivo. 
del enfoque diferenciado debido, principalmente, a la necesidad de que la definición del crimen de agresión debe estar en completa consonancia con el ECPI, los Elementos de los Crímenes, y las Reglas de Procedimiento y Prueba.

\section{El acto estatal de agresión}

El crimen de agresión indudablemente se encuentra vinculado al acto de agresión de un Estado contra otro. La determinación de un acto de agresión es la condición previa para que pueda comprobarse la existencia de un crimen de agresión; por tal motivo, cualquier definición relativa al crimen debe contemplar una definición del acto. En torno a esta cuestión, la PrepCom se ha encontrado con el resurgimiento de dos viejas posiciones, la de los países que defienden la introducción de una definición genérica del acto de agresión, y la de los que, por el contrario, prefieren la introducción de una definición específica. Para los primeros, la definición debe contemplar fórmulas amplias, generales y flexibles, que eviten entrar en detalles o en la elaboración de listados relativos a los actos susceptibles de ser considerados como de agresión. Dentro esta corriente encontramos las propuestas presentadas por la Federación de Rusia y Camerún.

Propuesta rusa:

A los efectos del presente Estatuto y a reserva de la previa determinación del Consejo de Seguridad de las Naciones Unidas de que el Estado interesado a cometido un acto de agresión, se entenderá por crimen de agresión cualquiera de los actos siguientes: planificar, preparar, iniciar o llevar a cabo una guerra de agresión. ${ }^{57}$

Propuesta de Camerún:

A los efectos del presente Estatuto y dejando a salvo la función desempeñada por el Consejo de Seguridad en materia de agresión de conformidad con el artículo 10 del presente Estatuto, se entenderá por crimen de agresión alguno de los actos siguientes, cometido por un individuo que esté en condiciones de controlar o dirigir la acción política o militar de un Estado: a) iniciar, b) planear, c) preparar, d) ordenar, o e) provocar el uso de la 
fuerza armada por dicho Estado, contra la soberanía, integridad territorial o la independencia política de otro Estado, cuando ese uso de la fuerza armada sea manifiestamente contrario a la Carta de las Naciones Unidas. ${ }^{58}$

La propuesta rusa retoma la definición incorporada en el Estatuto del Tribunal de Nüremberg y limita el acto en cuestión al inicio de una guerra de agresión. Por su parte, la propuesta de Camerún retoma la definición incorporada en el artículo 1o. de la resolución 3314 (XXIX) de 1974. Dentro de las definiciones de carácter genérico también pueden ser ubicadas aquéllas que limitan la existencia del acto a las guerras de agresión o ataques armados. La propuesta alemana es una de ellas, a saber:

1. A los fines del presente Estatuto, se entenderá por crimen de agresión cualquiera de los actos siguientes cometidos por una persona que esté en posición de ejercer el control o que pueda dirigir la acción política o militar de un Estado: a) iniciar o b) ejecutar un ataque armado dirigido por un Estado, cuando dicho ataque se haya emprendido en violación manifiesta de la Carta de las Naciones Unidas y que resulte en la ocupación efectiva por las fuerzas armadas del Estado atacante, o la anexión mediante el uso de la fuerza, del territorio de otro Estado o de parte de éste. ${ }^{59}$

La propuesta alemana limita considerablemente la determinación del acto, puesto que sólo prevé como agresión los actos encaminados a la ocupación efectiva o anexión de una parte o la totalidad del territorio del Estado agredido, es decir, deja de lado actos de suma gravedad que han sido reconocidos como agresiones, tales como los ataques aéreos, navales y terrestres, los bloqueos de puertos, así como las agresiones indirectas realizadas por bandas o grupos irregulares y mercenarios. Curiosamente, Alemania presentó esta propuesta en febrero de 1999, meses antes de que la Organización del Tratado del Atlántico Norte iniciara sus controvertidas operaciones militares "humanitarias" en la ex Yugoslavia.

De lado contrario a los Estados que defienden la redacción de una definición genérica se encuentran los que promueven la elaboración de una definición específica que, además de contener una conceptualización general, incluya un listado ilustrativo o taxativo de los principales actos

58 PCNICC/1999/INF/2. Propuesta de Camerún, p. 1. Una propuesta similar fue presentada por Grecia y Portugal. Véase PCNICC/1999/WGCA/DP.1, p. 1.

59 PCNICC/1999/DP.13. Propuesta de la República Federal de Alemania, p. 1. 
que pueden constituir agresión. Dicha posición ha sido plasmada en las propuestas de los países árabes y en la elaborada de manera conjunta entre Egipto e Italia; esta última es prácticamente idéntica a la primera.

Propuesta de los países árabes:

1. A los efectos del presente Estatuto, el crimen de agresión lo comete una persona que está en condiciones de ejercer el control o que puede dirigir acciones políticas o militares en su Estado, contra otro Estado, o que puede privar a personas de sus derechos a la libre determinación, la libertad y la independencia, en violación de la Carta de las Naciones Unidas, recurriendo a la fuerza armada para amenazar o violar la soberanía, la integridad territorial o la independencia política de ese Estado o los derechos inalienables de esas personas.

2. Entre los actos que constituyen agresión figuran los siguientes, ya vaya precedido o no de una declaración de guerra:

a) La invasión o el ataque por las fuerzas armadas de un Estado, del territorio de otro Estado, o cualquier ocupación militar, por provisional que sea, resultante de esa invasión o ataque, o cualquier anexión mediante el uso de la fuerza del territorio de otro Estado o parte de otro Estado;

b) El bombardeo por las fuerzas armadas de un Estado del territorio de otro Estado, o la utilización de cualesquiera armas por un Estado contra el territorio de otro Estado;

c) El bloqueo de los puertos o costas de un Estado por las fuerzas armadas de otro Estado;

d) Un ataque de las fuerzas armadas de un Estado contra las fuerzas armadas terrestres, navales o aéreas de otro Estado, o contra las flotas navales o aéreas de otro Estado;

e) La utilización de fuerzas armadas de un Estado que se encuentran en el territorio de otro Estado con el acuerdo del Estado receptor en violación de las condiciones previstas en el acuerdo, o cualquier prolongación de su presencia en ese territorio más allá de la terminación del acuerdo;

f) La acción de un Estado que autoriza que su territorio, que ha puesto a disposición de otro Estado, sea utilizado por ese Estado para perpetrar un acto de agresión contra un tercer Estado;

g) El envío por un Estado o por su cuenta de bandas, grupos, tropas no regulares o mercenarios que realicen actos de fuerza armada contra otro 
Estado de tal gravedad que equivalgan a los actos enumerados más arriba o su participación sustancial en ellos. ${ }^{60}$

Mientras que el párrafo 1 de la propuesta árabe introduce elementos novedosos al identificar a la amenaza como un acto de agresión, y a la privación de la libre determinación y de los derechos inalienables de las personas como objetivos del acto en cuestión, el párrafo 2 es una transcripción casi exacta del artículo 3o. de la resolución 3314 (XXIX). La amplitud y precisión de la propuesta árabe responde a la necesidad política de dichos Estados para contar con una disposición jurídica que disuada a muchos gobiernos intervencionistas (entiéndase las potencias del Consejo de Seguridad) de recurrir al uso arbitrario de la fuerza en contra de sus naciones como ha sido una costumbre a lo largo de la historia.

Con base en estas y otras propuestas, en 1999, el coordinador del GTCA elaboró un documento de debate conocido como Texto consolidado de las propuestas relativas al crimen de agresión, ${ }^{61}$ en el que se presentan dos opciones de definición del crimen de agresión, a saber: la Opción 1, que contiene tres variantes, y la Opción 2 que no presenta variante alguna:

Opción 1. A los efectos del presente Estatuto, [y con sujeción a la determinación que haga el Consejo de Seguridad respecto del acto de un Estado,] se entenderá por crimen de agresión [el empleo de la fuerza armada, incluido su inicio, por una persona que esté en condiciones de controlar o dirigir la acción política o militar de un Estado contra la soberanía, la integridad territorial o la independencia política de otro Estado en violación de la Carta de las Naciones Unidas] cualquiera de los actos siguientes cometidos por una persona que esté en condiciones de controlar o dirigir la acción política o militar de un Estado: Iniciar, o llevar a cabo. ${ }^{62}$

Pese a su generalidad, esta opción contempla el requisito de liderazgo, la conducta individual, el acto estatal de agresión, y además propor-

60 PCNICC/1999/DP.11. Propuesta presentada por Bahrein, Irak, la Jamahiriya Árabe Libia, el Líbano, Omán, la República Árabe Siria, el Sudán y el Yemen. La propuesta realiza por Egipto e Italia puede consultarse en PCNICC/1999/INF/2, pp. 2 y 3.

$61 \mathrm{PCNICC/1999/WGCA/RT.1.} \mathrm{Texto} \mathrm{consolidado} \mathrm{de} \mathrm{las} \mathrm{propuestas} \mathrm{relativas} \mathrm{al} \mathrm{cri-}$ men de agresión y condiciones para el ejercicio de la competencia.

62 La inclusión de corchetes sólo señala las diferentes fórmulas que se sugirieron, lo que no necesariamente indica una menor aceptación de esa parte del texto. 
ciona elementos para determinar la existencia del acto de agresión y al Estado agredido. La variante 1 de esta primera opción prevé otros actos constitutivos de agresión, tales como: el "empleo de la fuerza armada, un ataque armado, una guerra de agresión, y una guerra que constituya violación de tratados, acuerdos o seguridades internacionales". Además, incluye a la "participación en una conspiración o plan común para la perpetración" de alguno de estos actos como conducta individual susceptible de engendrar responsabilidad penal. Finalmente, amplía la gama de víctimas u objetivos sobre los que puede dirigirse el acto de agresión, a saber: "la privación a otros pueblos de sus derechos a la libre determinación, y de sus derechos inalienables".

La variante 2 propone una redacción genérica que sólo alude al acto estatal de agresión, y que además, limita el objetivo contra el cual se dirige el mismo a: "un ataque armado dirigido por un Estado contra la integridad territorial o la independencia política de un Estado... con el objetivo o el resultado de que las fuerzas armadas del Estado atacante ocupen militarmente, en todo en parte, el territorio de otro Estado o procedan a su anexión".

Finalmente, el texto de la variante 3 tiene como objetivo complementar la definición genérica propuesta en la variante 1, con la lista de actos constitutivos de agresión presentada en la propuesta de los países árabes. La lectura conjunta de las variantes 1 y 3 tienen como objetivo ofrecer una definición mixta o específica del crimen de agresión. El elemento de mayor novedad introducido por la variante 3 es la condición de que los actos allí enumerados sean de gravedad suficiente para ser determinados como agresión. La determinación de la gravedad suficiente apareció por primera vez en la propuesta de definición presenta por Egipto e Italia (1997) y retomada en la realizada por Camerún (1998), dando inicio a un polémico debate (sobre la cuestión del umbral o the threshold issue) en el que se discute la pertinencia de dicho término en la definición final del crimen de agresión, en razón de la naturaleza eminentemente política de la determinación de tal gravedad.

Ahora bien, la Opción 2 propone una definición sumamente general, en la que se contempla el acto estatal de agresión y la conducta individual, dejando el requisito de liderazgo como un elemento sobreentendido, es decir, no se necesita hacer mención del mismo ya que es ampliamente reconocido y aceptado que el crimen en cuestión es un crimen de líderes. Así, la Opción 2, dispone que: "A los efectos del presente Estatu- 
to y con sujeción a la determinación previa por el Consejo de Seguridad de que el Estado de que se trate ha cometido un acto de agresión, se entenderá por crimen de agresión el acto de planificar, preparar, iniciar o llevar a cabo una guerra de agresión".

Esta opción retoma la redacción del Estatuto de Nüremberg, la propuesta rusa y el enfoque monístico. Asimismo, dicha opción es ampliamente aceptada por buena parte de los países miembros del Consejo de Seguridad de las Naciones Unidas y muchos de sus aliados más cercanos.

Como puede observarse, el debate sostenido durante los trabajos de la PrepCom en torno a la definición del crimen de agresión no se fundamenta en la definición del crimen en sí mima, sino en la definición del acto de agresión. Parecería que dicha discusión ya había sido superada con la adopción de la resolución 3314 (XXIX) de 1974, sin embargo, debido a la trascendencia del crimen de agresión sobre la responsabilidad penal individual de muchos jefes de Estado y de gobierno y altos funcionarios políticos y militares, los Estados han mostrado una actitud reticente a aceptar la definición existente y han buscado, por todo los medios a su alcance, sacar el mejor provecho posible de una definición genérica que pueda interpretarse de manera elástica a fin de evitar que sus líderes nacionales puedan ser llamados a rendir cuentas por sus actos ante la CPI.

Misma problemática se ha presentado en el debate relativo a las condiciones, en las cuales la CPI ejercerá su competencia sobre el crimen de agresión. Por una parte, están los que defienden la facultad del Consejo de Seguridad para determinar la existencia de actos agresión y, por otro lado, los que promueven la autonomía total de la CPI en la materia. A continuación revisaremos dicha problemática.

\section{Condiciones bajo las cuales la CPI ejercerá su competencia} sobre el crimen de agresión: entre la autonomía de la Corte y la dependencia hacia el Consejo de Seguridad

Los trabajos de la PrepCom se han visto seriamente retrasados por la falta de acuerdo entre los Estados para fijar las condiciones en que la CPI ejercerá su competencia sobre el crimen de agresión. Para que la CPI pueda ejercer competencia sobre tal crimen se requiere necesariamente la determinación de existencia de un acto de agresión. El acto de agresión es un acto de un Estado contra otro, por tal motivo, su determinación no 
puede ser realizada por la CPI, ya que esta instancia penal únicamente ejerce competencia sobre individuos. En este sentido, el acto debe ser determinado por un órgano externo.

Durante la Conferencia Diplomática de Roma, en la que se adoptó el ECPI, el tema en cuestión dio origen a dos posturas políticas. Por un lado, la de los miembros permanentes del Consejo de Seguridad que defendían la facultad del Consejo para determinar la existencia de actos de agresión con base en criterios tales como: a) que la CPI debe ejercer su competencia de forma compatible con la Carta de las Naciones Unidas, y que la única solución compatible es respetar las facultades conferidas al $\mathrm{CS}$; b) que el CS es el órgano más adecuado para valorar los elementos políticos que conlleva la apreciación del acto de agresión y para evitar su utilización con fines propagandísticos, y c) que no afectaría la independencia e integridad de la Corte pues, pese a su discrecionalidad, el CS adopta sus decisiones de conformidad con la Carta y el derecho internacional. Y por otro lado la de los países principalmente en vías de desarro1lo, que defienden la independencia de la CPI con base en: a) que la Carta de las Naciones Unidas confiere responsabilidad primordial, pero no exclusiva al CS. La AG y la CIJ han afirmado y ejercido su competencia para aceptar la comisión de actos de agresión; b) que el CS, en sesenta años de historia, jamás ha constatado una sola agresión; c) que se condicionaría el funcionamiento de un órgano judicial a una decisión política adoptada dentro de un amplísimo margen de discrecionalidad, y $d$ ) que el derecho a veto de los miembros permanentes del CS podría repercutir en las situaciones susceptibles de constituir agresión. ${ }^{63}$ La falta de acuerdo en torno a este tema ocasionó la negativa de Estados Unidos y China para ratificar el Estatuto de Roma.

Estados Unidos "estaba dispuesto a aceptar la inclusión de la agresión en el Estatuto con la condición de que el Consejo de Seguridad de-

63 En febrero de 2003, Cuba presentó una propuesta a la Asamblea de Estados Parte de la CPI, en la que se señalaba que: La Corte podrá ejercer su jurisdicción sobre un crimen de agresión de conformidad con las disposiciones del presente Estatuto, incluidas las disposiciones de los artículos 12, 13, 17 y 18. La falta de un pronunciamiento del Consejo de Seguridad sobre la existencia de un acto de agresión cometido por el Estado de que se trate no impedirá el ejercicio de la jurisdicción de la Corte sobre el caso en cuestión. Documento: ICC-ASP/1/L.4. 
terminara en primera instancia la existencia de un acto de agresión". ${ }^{64} \mathrm{El}$ propósito estadounidense era claro, otorgar al CS una facultad preclusiva sobre el crimen de agresión que impidiera a la CPI ejercer su competencia sobre dicho crimen en determinadas circunstancias, es decir, cuando el acto de agresión pudiera acarrear la responsabilidad penal individual de los nacionales de alguno de los miembros permanentes del Consejo. Otorgar una facultad preclusiva al CS tendría como consecuencia "la creación de dos estándares legales: inmunidad efectiva sobre el crimen de agresión para los miembros permanentes del Consejo de Seguridad, y, dada la dificultad de definir el crimen de agresión, una responsabilidad penal impredecible para los nacionales de los demás Estados". ${ }^{65}$

Sin duda alguna, estamos ante un nuevo capítulo del debate referente a la supuesta facultad exclusiva del Consejo de Seguridad en la determinación de actos de agresión. Sin embargo, actualmente el tema cobra mayor trascendencia en razón de sus implicaciones jurídico-políticas para la plena impartición de la justicia penal internacional y el funcionamiento integral de la CPI. Tanto la justicia como la Corte no pueden estar a expensas de las decisiones eminentemente políticas del CS, ya que se estaría yendo en contra de uno de los principios máximos de la justicia y el derecho, es decir, otorgar a las víctimas de un crimen internacional la seguridad jurídica necesaria de que los daños sufridos serán reparados y que los responsables serán sancionados por sus actos. Asimismo, el debate se torna ocioso, ya que ha quedado claramente comprobado que las funciones y determinaciones realizadas por CS son políticas, mientras que las de la CIJ y, en este caso, las de la CPI son jurídicas y encaminadas a dilucidar la responsabilidad internacional del Estado o del individuo.

En este sentido, "sería imprudente sostener que las calificaciones del Consejo de Seguridad son preceptivas y vinculantes para otros órganos, especialmente los judiciales, llamados a pronunciarse sobre la responsabilidad de un Estado [o individuo] cuyo origen está en un acto de agre-

64 A. Schabas, William, "United States Hostility to the International Criminal Court: It's all about the Security Council", European Journal of International Law, vol. 15, núm. 4, 2004, p. 703.

65 Partan, Daniel G. y Rogic, Predrag, "Sovereignty and International Criminal Justice”, Revista Colombiana de Derecho Internacional, Bogotá, núm. 1, junio de 2003, p. 65 . 
sión". ${ }^{66}$ Sin embargo, como sostiene el jurista mexicano Juan Carlos Velázquez Elizarrarás,

el Estatuto de Roma y su jurisdicción penal internacional no se encuentran en el terreno de lo ideal, sino que se sitúan ante verdaderas relaciones de poder, a las cuales no puede estar ajena la negociación internacional. No puede culparse a la CPI de una situación que está más allá de sus posibilidades, antes se debe comenzar por avanzar en una reforma del sistema y los instrumentos de Naciones Unidas, tarea que numerosos Estados eluden $\mathrm{y}$, por razones prácticas, se acoplan al sistema y buscan hacerse de los recursos de la cooperación internacional, generalmente de tipo económico, dejando de lado los asuntos más delicados y sensibles, como lo es en este caso el crimen de agresión y otros hechos internacionalmente ilícitos que le son asociados. ${ }^{67}$

Conscientes de que el éxito de los trabajos realizados por la PrepCom en materia del crimen de agresión se encuentra estrechamente vinculado a la negociación y voluntad política, muchos Estados han adoptado una posición conciliadora tendiente a compatibilizar las funciones del CS con las de la CPI. En el documento titulado Condiciones para el Ejercicio de la Competencia, que forma parte del Texto Consolidado de Propuestas relativas al Crimen de Agresión, el coordinador del GTCA presentó algunas propuestas sobre el tema con base en las aportaciones realizadas por los Estados participantes.

Dicho documento se encuentra divido en tres grandes opciones. La Opción 1 contempla seis modalidades a través de las cuales la Corte puede ejercer su competencia sobre el crimen de agresión, a saber:

1. La Corte ejercerá su competencia... conforme al artículo 13 del Estatuto. ${ }^{68}$

66 Remiro Brotóns, Antonio, op. cit., nota 40, p. 6.

67 Velázquez Elizarrarás, Juan Carlos, El derecho internacional penal, México, UNAM, FCPyS, p. 5.

68 El artículo 13 del ECPI dispone que: "La Corte podrá ejercer su competencia respecto de cualquiera de los crímenes a que se refiere el artículo 5o. de conformidad con las disposiciones del presente Estatuto si: a) Un Estado Parte remite al fiscal, de conformidad con el artículo 14, una situación en que parezca haberse cometido uno o varios de esos crímenes; b) El Consejo de Seguridad, actuando con arreglo a lo dispuesto en el Capítulo VII de la Carta de las Naciones Unidas, remite al Fiscal una situación en que pa- 
2. El Consejo de Seguridad determinará la existencia un acto de agresión cometido por el Estado del que sea nacional el imputado, de conformidad con las disposiciones pertinentes de la Carta de las Naciones Unidas, antes de que la Corte abra las diligencias con respecto al crimen de agresión.

3. El Consejo de Seguridad con arreglo a lo dispuesto en el artículo 13 b) del Estatuto, tomará ante todo una decisión en la que se determine que el Estado del que sea nacional el imputado ha cometido un acto de agresión.

4. La Corte, cuando reciba una denuncia relativa al crimen de agresión con arreglo al artículo 13 a) o c), pedirá primero al Consejo de Seguridad... que determine si el Estado del que sea nacional el imputado ha cometido un acto de agresión.

5. El Consejo de Seguridad tomará la decisión dentro de los [6] [12] meses siguientes.

6. El Presidente del Consejo de Seguridad notificará sin demora esta decisión, por carta, al Presidente de la Corte Penal Internacional.

Como puede observarse, esta opción otorga al Consejo de Seguridad la facultad de determinar la existencia de actos de agresión con base en las atribuciones que le ha conferido la Carta de las Naciones Unidas, o a petición de la propia Corte. El único límite que se contempla al accionar del Consejo es el tiempo con que cuenta para determinar la existencia del acto. La variante 1, anexa a la Opción 1, prevé el ejercicio independiente de la competencia de la Corte en aquellos casos en que el CS no emita su determinación en el periodo previsto. Por su parte, la variante 2 dispone que ante la falta de determinación por parte del CS, la Corte podrá solicitar a la AG que realice una recomendación al respecto en un periodo máximo de doce meses. En ambas variantes se contempla que las decisiones del CS y la AG no afectarán en modo alguno la independencia de la Corte en el ejercicio de su competencia con respecto al crimen de agresión.

Por su parte, la Opción 2 prevé tres supuestos en los que la Corte puede ejercer competencia sobre el crimen en cuestión, a saber: 1. previa determinación de un acto de agresión por parte del CS; 2 . ante toda denuncia relativa al crimen de agresión que sea presentada a la Corte, se procederá a verificar si existe una determinación previa del CS; de no

rezca haberse cometido uno o varios de esos crímenes; o c) El fiscal ha iniciado una investigación respecto de un crimen de ese tipo de conformidad con lo dispuesto en el artículo 15 ". 
existir tal, la Corte solicitará al Consejo que emita dicha determinación, y 3. si en un plazo de doce meses el CS no emite determinación alguna, la Corte podrá proceder a abrir diligencias. Como puede apreciarse, esta opción desestima el recurso a la AG.

Finalmente, la Opción 3, redactada en un párrafo único, dispone que la Corte ejercerá su competencia, "siempre y cuando, el Consejo de Seguridad de las Naciones Unidas haya determinado previamente la existencia de un acto de agresión cometido por el Estado de que se trata". Dicha opción otorga una facultad preclusiva al CS.

Cualquier definición sobre el crimen de agresión y las condiciones en que la CPI ejercerá su competencia que pretenda ser políticamente aceptada deberá otorgar facultades al Consejo de Seguridad en la determinación del acto de agresión. Para algunos doctrinarios y Estados dicho razonamiento sería contrario al espíritu de independencia con que fue creada la CPI, sin embargo, si se desea que los trabajos de la PrepCom tengan un final satisfactorio que se traduzca en la introducción de una disposición relativa al crimen de agresión en el ECPI, se deberán flexibilizar las posiciones políticas y doctrinales de carácter radical. Otorgar facultades al CS no constituye per se que la independencia de la CPI se vea disminuida, por el contrario, más afectado se vería el funcionamiento de la Corte por no contar, por un lado, con una definición relativa al máximo crimen contra el derecho internacional y, por otro lado, porque las grandes potencias, al no ver vistas satisfechas sus pretensiones, paralicen $\mathrm{o}$ abandonen las discusiones en la materia.

A final de cuentas, la política internacional es el vehículo para lograr el avance de la comunidad internacional en todos sus ámbitos, sin embargo, corresponde al derecho internacional confirmar esos avances e impedir que se retroceda. La política internacional definirá el crimen de agresión y las condiciones en que la CPI ejerza su competencia sobre el mismo, por su parte, el derecho internacional proveerá a la Corte de los instrumentos jurídicos necesarios para que la definición política pueda ser interpretada jurídicamente y, con ello, tener la posibilidad de ampliar su margen de acción y competencia sobre el crimen de agresión.

A escaso un año de que se cumpla el plazo marcado en los artículos 121 y 123 del ECPI para que el mismo pueda ser revisado y enmendado, los resultados obtenidos por la PrepCom en la definición del crimen de agresión han sido realmente magros. Las dos posiciones dominantes en cuanto al enfoque apropiado para una definición del crimen y las condi- 
ciones para el ejercicio de competencia parecen irreconciliables. El problema se agudiza si se toma en cuenta que Estados Unidos, China, y otros países, que no ratificaron el Estatuto de Roma pero que influyen de manera determinante en los trabajos de la PrepCom, se encuentran ejerciendo una fuerte presión diplomática sobre muchos países para que, en caso de que se llegue a un acuerdo sobre el tema, se favorezca la posición del Consejo de Seguridad en la determinación del acto de agresión, es decir, para que se adopte e institucionalice la facultad preclusiva del Consejo sobre el crimen en cuestión. Asimismo, Estados Unidos ha utilizado su capacidad económica para allegarse el apoyo de un buen número países en su campaña de desprestigio contra la Corte Penal Internacional, y para que firmen acuerdos bilaterales que garanticen que sus nacionales no serán llevados ante la Corte por la comisión de alguno de los crímenes sobre los que tiene competencia.

El problema de fondo ha dejado de ser jurídico para convertirse en una cuestión eminentemente política. La posición conciliadora de la PrepCom no es suficiente. La Comisión debe asumir una participación activa en la negociación de la definición del crimen a través de iniciativas y propuestas propias formuladas de tal manera que obliguen a los Estados a avanzar en los debates en la materia.

\section{REFLEXIONES FINALES}

El debate en torno a la definición del acto y crimen de agresión es un ejemplo más de que el derecho y la política internacionales no pueden ser estudiados y plenamente comprendidos de manera aislada. En 1945 las potencias vencedoras de la Segunda Guerra Mundial definieron de manera rápida y más o menos precisa el crimen de agresión ya que sus intereses políticos y de "justicia" así se los exigían. En 1974 aceptaron una definición del acto de agresión, ya que la misma sólo tiene un carácter declarativo y sus alcances y significado aún siguen siendo objeto de debate. Desde 1998, y hasta nuestros días, los intereses políticos de los Estados han impedido que la Corte Penal Internacional y la comunidad internacional cuenten con una definición y tipificación precisa del crimen supremo contra el derecho de gentes.

La cuestión de la agresión hace mucho tiempo dejó de ser un debate meramente jurídico para convertirse en una cuestión eminentemente política, que sólo avanzará en la medida en que la negociación internacional 
logre conciliar posturas e intereses. En el proceso de negociación desempeñarán un papel sumamente importante la Organización de las Naciones Unidas y la Comisión Preparatoria de la Corte Penal Internacional como foros internacionales de discusión, y la participación activa, a través de propuestas y reuniones, realizadas a iniciativa propia por parte de todos aquellos Estados que se encuentran en favor de la introducción de una definición del crimen de agresión en el Estatuto de Roma.

El problema de fondo no es la definición ni las condiciones en que ejercerá competencia la CPI, sino los intereses políticos que se encuentran de por medio. A las grandes potencias no les interesa qué tipo de definición se adopte, siempre y cuando el Consejo de Seguridad sea el encargado de determinar la existencia de un acto de agresión. Es decir, mientras que sus nacionales no corran el riesgo de ser llevados ante la Corte. Por su parte, las potencias medianas, las cuales han sabido sacar provecho del status quo internacional y que por lo regular nunca tienen problemas con otros Estados, son conscientes de que una definición del crimen de agresión políticamente viable necesariamente tiene que incluir al Consejo de Seguridad. Finalmente, para los países débiles y para aquéllos que se encuentran en constante enfrentamiento con las grandes potencias, la opción más viable es la adopción de una definición precisa que no pueda ser utilizada en su contra de manera arbitraria, y que no contemple la participación del Consejo de Seguridad.

Mientras los Estados concilian intereses y alcanzan acuerdos, la comunidad internacional sigue careciendo de una definición del crimen de agresión, ocasionando un vacío jurídico que ha permitido que muchos Estados recurran al uso de la fuerza armada de manera arbitraria, y que sus líderes políticos y militares gocen de impunidad por sus actos. 